\title{
Signature of life on exoplanets: Can Darwin produce false positive detections?
}

\author{
F. Selsis ${ }^{1,2}$, D. Despois ${ }^{2}$, and J.-P. Parisot ${ }^{2}$ \\ 1 Centro de Astrobiología (INTA-CSIC), Ctra. de Ajalvir, km. 4, 28850, Torrejón de Ardoz, Madrid, Spain \\ 2 Observatoire de Bordeaux, BP 89, 33270, Floirac, France
}

Received 18 May 2001 / Accepted 19 March 2002

\begin{abstract}
Darwin (ESA) and Terrestrial Planet Finder-TPF (NASA) are two projects of space telescopes aiming at the detection of extra-solar terrestrial planets and some of their atmospheric components. In particular, they will be sensitive to the $9.6 \mu \mathrm{m}$ band of $\mathrm{O}_{3}$ which may be the signature of an $\mathrm{O}_{2}$-rich atmosphere produced by photosynthetic life forms. In this paper, we point out that $\mathrm{O}_{2}$, and hence $\mathrm{O}_{3}$, can also be produced by photochemistry and we investigate the risk of "false positive" detection of life incurred by these missions. For this purpose, we have developed new photochemical and radiative-convective models of terrestrial planet atmospheres. By modelling the photochemistry of some realistic atmospheres, (including present and past Earth and Mars) we show that $\mathrm{O}_{2}$-rich atmospheres (up to $5 \%$ ) and IR absorbing $\mathrm{O}_{3}$ layers can build up without life from $\mathrm{H}_{2} \mathrm{O}$ and $\mathrm{CO}_{2}$ photolysis. However, Darwin can still provide a reliable way to detect, through their mid-infrared signatures, ecosystems which have developed oxygenic photosynthesis. Indeed, the two photochemical sources of $\mathrm{O}_{2}$ are shown to interfere with each other; second, when the $\mathrm{CO}_{2}$ pressure is high enough (>50 mbar) to produce appreciable amounts of $\mathrm{O}_{2}$ and $\mathrm{O}_{3}$, it also masks the $\mathrm{O}_{3}$ feature; and third, the by-products of $\mathrm{H}_{2} \mathrm{O}$ photolysis destroy $\mathrm{O}_{3}$. As a result, whereas the unique detection of $\mathrm{O}_{2}$ remains ambiguous, the simultaneous infrared detection of $\mathrm{O}_{3}, \mathrm{CO}_{2}$ and $\mathrm{H}_{2} \mathrm{O}$, provided by Darwin, is established to be a robust way to discriminate photochemical $\mathrm{O}_{2}$ production from biological photosynthesis: none of the atmospheres modelled exhibits this "triple signature", even in the most extreme "high risk" cases.
\end{abstract}

Key words. astrobiology - planets and satellites: general - infrared: solar system - stars: planetary systems

\section{Introduction}

Two space projects, Darwin (Léger et al. 1996) and TPF (Beichman et al. 1999) are presently under study to search for terrestrial exoplanets and signatures of life in their atmosphere. Molecular oxygen $\mathrm{O}_{2}$ and the closely related species ozone $\mathrm{O}_{3}$ will be looked for as tracers of oxygenic photosynthesis, by analogy with Earth. We address here the question of the real meaning of $\mathrm{O}_{2}$ and $\mathrm{O}_{3}$ detections on a planet, and the possibility of "false positive detections" (i.e. cases where abiotic (photochemical) processes might mimic the biogenic production of $\mathrm{O}_{2}$ and $\mathrm{O}_{3}$ ). Our purpose is to answer the following questions:

- What level of atmospheric $\mathrm{O}_{2}$ can be built up in the absence of life from photochemical processes?

- Can abiotic $\mathrm{O}_{2}$ results in a detectable signature of $\mathrm{O}_{3}$ in the mid-infrared range $(5-20 \mu \mathrm{m})$ ?

- Can we unambiguously identify in those cases the abiotic origin of $\mathrm{O}_{2}$ and $\mathrm{O}_{3}$ ?

Send offprint requests to: F. Selsis,

e-mail: selsis@observ.u-bordeaux.fr
To investigate the risk due to abiotically produced $\mathrm{O}_{2}$, we have selected three types of atmospheres, which present one or both of the main photochemical processes for its production: photodissociation of $\mathrm{CO}_{2}$ and $\mathrm{H}_{2} \mathrm{O}$. These types are humid $\mathrm{CO}_{2}$ dominated atmospheres (cases A-D), dry $\mathrm{CO}_{2}$ atmospheres, (E, F) and a humid atmosphere with permanent water supply and hydrogen escape $(\mathrm{G})$.

The first type we will consider is $\mathrm{CO}_{2}$ dominated atmospheres with water vapor rising from a moist saturated surface. This very important case is believed to correspond to the early stages of the atmosphere of all the three terrestrial planets Venus, Earth and Mars. It also includes Mars at the present time, and a possible future, terraformed state of this planet. We will study 4 cases with $P_{\mathrm{CO}_{2}}$ from 6 to 3200 mbar. Sensitivity of the model to the parameters and processes included was checked in case A (Mars).

The second type is a dry $\mathrm{CO}_{2}$ atmosphere. We consider this type because, due to the lack of chemical destruction path using the $\mathrm{OH}$ radical, it is expected to maximize the abiotic $\mathrm{O}_{2}$ and $\mathrm{O}_{3}$ production as compared to the humid $\mathrm{CO}_{2}$ atmosphere. This case is the most favorable for abiotic $\mathrm{O}_{2}$ production. The 2 cases considered are for 
$P_{\mathrm{CO}_{2}}=4000$ (large $\mathrm{O}_{2}$ content) and 50 mbar (compromise between $\mathrm{O}_{2}$ production and $\mathrm{O}_{3}$ detectability).

The third case, suggested by J. Schneider, is an atmosphere with a permanent $\mathrm{H}_{2} \mathrm{O}$ influx at high altitudes, where water photolysis can occur. When this delivery, provided by comets or small ice particles of cometary origin, is associated with hydrogen escape, this can lead to an $\mathrm{O}_{2}$ accumulation.

After reviewing the cases of abiotic $\mathrm{O}_{2}$ and $\mathrm{O}_{3}$ production in the solar system today, we present the $\mathrm{CO}_{2}$ and $\mathrm{H}_{2} \mathrm{O}$ photodissociation processes responsible for it, and the sources of $\mathrm{CO}_{2}$ and $\mathrm{H}_{2} \mathrm{O}$ in the present and the past of the terrestrial planets (Sect. 3.3). The numerical tools developed to study these present and past atmospheres of terrestrial planets in the solar system and around other stars are described in Sect. 4: the photochemical model PHOEBE and the infrared spectrum computation tool LWT. The results of our simulations are presented Sect. 5.

Two processes not taken into account in previous works prove to be important: the retroaction of chemistry on the vertical temperature profile, and the disappearance of the ozone mid-IR signature for high $P_{\mathrm{CO}_{2}}$ (above $\sim 50$ mbar). These results are discussed in Sect. 6 with respect to the remote detection of life signatures through Darwin or TPF. We conclude from these results that the real risk of "false positive" detection of ecosystems appears very limited, which makes the triple $\mathrm{O}_{3}-\mathrm{H}_{2} \mathrm{O}-\mathrm{CO}_{2}$ IR signature a robust indicator of life.

\section{Observational search for exoplanets and signatures of life}

The existence of other planetary systems, discussed already by ancient greek philosophers, has only been proved very recently, first around pulsars (Wolszczan \& Frail 1992), then around solar type stars (Mayor \& Queloz 1995). In this latter case, the discovered planets are massive (of the order of a Jupiter mass) and likely to be giant gaseous planets, which at least proved to be the case for HD 209458b (Charbonneau et al. 2000). Up to now, 76 planets with masses above 0.2 Jupiter mass have been found around 68 main-sequence stars ${ }^{1}$. Recently, the discovery of 15 "free floating" massive planets (i.e. not orbiting around a star) has been announced in a star forming region (Zapatero Osorio et al. 2000).

The search for smaller planets of terrestrial type rises considerable scientific and philosophical interest, but is technically much more difficult. Among the ambitious projects aimed at their detection, the space observatories under study by ESA (Darwin; Léger et al. 1996) and by NASA (TPF; Beichman et al. 1999) are based on direct detection in the near infrared through a "nulling interferometer" (Bracewell 1978). Other concepts for indirect search of terrestrial planets are the space projects Corot (Rouan et al. 1998), Eddington (Deeg et al. 2000) and Kepler (Borucki et al. 1997).

\footnotetext{
1 See http://www.obspm.fr/encycl/encycl.html for an update
}

As soon as photons coming from the planet can be distinguished from those coming from the star, a spectral analysis is feasible within the available signal-to-noise ratio. The physical and chemical properties of the planets and their atmosphere can be studied. The recent detection of the atmosphere of a "hot Jupiter" in absorption during a transit is the first spectral information gained on the atmosphere of an exoplanet (Charbonneau et al. 2001). As life on Earth has strongly modified the planet (atmosphere, oceans, surface), can we use this fact to distinguish spectroscopically the presence of similar life on another planet? In the particular case of Earth, $\mathrm{O}_{2}$ is fully produced by the biosphere: less than 1 ppm coming from abiotic processes (Walker 1977). In a famous paper, Sagan et al. (1993) analyzed a spectrum of the Earth taken by the Galileo probe, searching for signatures of life. They conclude that the large amount of $\mathrm{O}_{2}$ and the simultaneous presence of $\mathrm{CH}_{4}$ traces is suggestive of biology. Moreover, the detection of a widespread red-absorbing pigment with no plausible mineral origin supports the hypothesis of biophotosynthesis. Owen (1980) suggested to search for $\mathrm{O}_{2}$ whereas Angel (1986) has suggested to consider rather $\mathrm{O}_{3}$ and its signature in the mid-infrared range around $10 \mu \mathrm{m}$. Paetzold (1962) and Léger et al. (1993) have investigated the feature of $\mathrm{O}_{3}$ as a tracer of $\mathrm{O}_{2}$ in the atmosphere of exoplanets. This concept is at the root of the spectroscopic design of Darwin, as proposed to ESA by Léger et al. (1996), and of TPF (Terrestrial Planet Finder, Beichman et al. 1999).

For Darwin, all the volatile ingredients and products of oxygenic photosynthesis lead, directly or indirectly, to infrared spectral signatures in the instrument's window:

$$
2 \mathrm{H}_{2} \mathrm{O}^{*}+\mathrm{CO}_{2}+\text { photons } \longrightarrow \mathrm{CH}_{2} \mathrm{O}+\mathrm{H}_{2} \mathrm{O}+\mathrm{O}_{2}^{*} \text {. }
$$

(As pointed out by the asterisks, photosynthetic $\mathrm{O}_{2}$ is made of oxygen atoms extracted from water.)

The absorption lines of $\mathrm{H}_{2} \mathrm{O}, \mathrm{CO}_{2}$ and, as a tracer of the oxygen, $\mathrm{O}_{3}$, will be simultaneously searched for: this is what we call the triple signature. For the project TPF, an alternative option is to search for $\mathrm{O}_{2}$ in the visible range (Nisenson \& Papaliolios 2001).

To validate the concept of Darwin and TPF with respect to the search for extraterrestrial life, it is compulsory to understand both the risk of a "false positive" result (where an abiotic process is mistakenly interpreted as a signature of life) and of a "false negative" result (when a planet contains life forms but does not produce any characteristic signature). When using the criterion of $\mathrm{O}_{2}$ or $\mathrm{O}_{3}$, false negative cases are clearly possible: on Earth itself, almost 2 Gyr are thought to separate the first traces of life -3.7 Gyr BP (before present) (Rosing 1999) and maybe earlier (Mojzsis et al. 1996) - from the epoch where $\mathrm{O}_{2}$ has reached detectable levels in the atmosphere - 2.3-1.9 Gyr BP (Holland 1994). Furthermore, even oxygen-rich atmospheres can fail to lead to a detectable signature of ozone in the Darwin spectra (Selsis 2000a, 2002). 


\section{3. $\mathrm{O}_{2}$ and $\mathrm{O}_{3}$ in abiotic conditions}

The problem of abiotic production of $\mathrm{O}_{2}$ with regard to the relevance of $\mathrm{O}_{2}$ as a tracer of life has been addressed by several previous authors. Léger et al. (1999) have rejected the hypothesis of an oxygen-rich atmosphere from infalling comets, answering questions stressed by Noll et al. (1997). Ollivier (1999) proposed to search simultaneously for $\mathrm{H}_{2} \mathrm{O}$ and $\mathrm{O}_{3}$. Schindler \& Kasting (2000) have discussed the false positive problem in the frame of radiative transfer computations of IR methane and ozone lines, but without modelling the photochemical production of these species. The work of Kasting (1988) on the evolution of Venus atmosphere stresses a case where an atmosphere can transiently be rich in $\mathrm{O}_{2}$ through abiotic phenomena whereas having both $\mathrm{H}_{2} \mathrm{O}$ and $\mathrm{CO}_{2}$ present in detectable quantities. Chassefière \& Rosenqvist ${ }^{2}$ (1995) made a pioneer study of $\mathrm{O}_{2}$ production rates in $\mathrm{CO}_{2}$ dominated humid atmospheres, and applied it to early stages of Mars. A preliminary report of the present work and questions related to Darwin have been published by Selsis (2000a). Details of the model are described by Selsis (2000b).

Apart from the Earth, $\mathrm{O}_{2}$ is present in the atmosphere of other bodies of the Solar System (Sect. 3.1). In all cases its presence can be attributed to abiotic processes, mainly $\mathrm{CO}_{2}$ and $\mathrm{H}_{2} \mathrm{O}$ photodissociation (Sect. 3.3).

\section{1. $\mathrm{O}_{2}$ and $\mathrm{O}_{2}$ in the solar system today}

\subsubsection{Venus}

The oxygen airglow emission has been observed in the visible (dayglow: Connes et al. 1979; nightglow: Slanger et al. 2001) and in the $1.27 \mu \mathrm{m}$ band (Connes et al. 1979). However it is not possible to estimate the $\mathrm{O}_{2}$ column density from these observations. Indeed, this IR airglow arises from the decay of $\mathrm{O}_{2}\left({ }^{1} \Delta\right)$ which can be produced by several processes: $\mathrm{O}_{3}$ photolysis, atomic oxygen recombination, reaction of $\mathrm{O}_{3}$ with $\mathrm{Cl}$ radicals. Several attemps to detect $\mathrm{O}_{2}$ allowed to infer upper limits on its abundance, equivalent to uniform mixing ratios of $2 \times 10^{-6}$ (Traub \& Carleton 1974) and $3 \times 10^{-7}$ (Trauger \& Lunine 1983) Two in situ measurements by Pioneer Venus gave surprising mixing ratios: $(4.4 \pm 2.5) \times 10^{-5}$ at $52 \mathrm{~km}$ altitude, and $(1.6 \pm 0.7) \times 10^{-5}$ at $42 \mathrm{~km}$ (Oyama et al. 1980); but these detections have been discounted by several authors (von Zahn et al. 1983; Krasnopolsky \& Zahn 1986). Recently, Mills (1999) gave an upper limit of $3 \times 10^{-6}$ for the $\mathrm{O}_{2}$ mixing ratio above the 300 mbar level.

\subsubsection{Mars}

Molecular oxygen was first detected by Barker (1972) by the Doppler-shifted $760 \mathrm{~nm}$ lines and the same year by Carleton \& Traub (1972). Using the same method, Trauger \& Lunine (1983) inferred a more precise estima-

\footnotetext{
${ }^{2}$ See also the commentary to this work done by Kasting (1995).
}

Table 1. Observations of $\mathrm{O}_{2}$ and $\mathrm{O}_{3}$ in the solar system. For the martian atmosphere, equivalent mixing ratios are calculated with a mean total column density of $2.08 \times 10^{23} \mathrm{~cm}^{-2}$ corresponding to a mean surface pressure of 5.6 mbar. $(*)$ The surface mixing ratio was measured by Viking at a 7.5 mbar pressure.

\begin{tabular}{|c|c|c|}
\hline $\begin{array}{l}\text { species and } \\
\text { references }\end{array}$ & $\begin{array}{l}\text { column density } \\
\mathrm{cm}^{-2}\end{array}$ & $\begin{array}{l}\text { equivalent } \\
\text { mixing ratio }\end{array}$ \\
\hline \multicolumn{3}{|c|}{ Mars } \\
\hline $\mathrm{O}_{2}$ & $\left(\times 10^{20}\right)$ & \\
\hline Barker (1972) & $(2.6 \pm 0.2)$ & 0.0012 \\
\hline Carleton \& Traub (1972) & $(2.8 \pm 0.3)$ & 0.0013 \\
\hline Trauger \& Lunine (1983) & $(2.3 \pm 0.1)$ & 0.0011 \\
\hline \multicolumn{3}{|l|}{ Owen et al. } \\
\hline (Viking - in situ) (1977) & & $0.0013(*)$ \\
\hline $\mathrm{O}_{2}$ & $\left(\times 10^{15}\right)$ & $\left(\times 10^{-8}\right)$ \\
\hline Espenak et al. (1991) & $4.0 \pm 1.3$ & 1.9 \\
\hline Clancy et al. (1999) & $5.4-10.8$ & $2.6-5.2$ \\
\hline \multicolumn{3}{|c|}{ Venus } \\
\hline $\mathbf{O}_{2}$ : Mills (1999) & - & $<3 \times 10^{-6}$ \\
\hline \multicolumn{3}{|c|}{ Icy satellites } \\
\hline \multicolumn{3}{|c|}{ Ganymede (G), Europe (E), Rhea (R), Dione (D) } \\
\hline \multicolumn{3}{|c|}{ Atmospheric $\mathrm{O}_{2} \quad\left(\times 10^{14}\right)$} \\
\hline \multirow[t]{2}{*}{ Hall et al. (1998) } & $2.4-14(\mathrm{G})$ & - \\
\hline & $1-10(\mathrm{E})$ & - \\
\hline $\mathrm{O}_{2}$ trapped in ice & $\left(\times 10^{16}\right)$ & \\
\hline Noll et al. (1996) & $4.5(\mathrm{G})$ & - \\
\hline Noll et al. (1997) & $1-6(\mathrm{R} \& \mathrm{D})$ & - \\
\hline
\end{tabular}

tion of the mean $\mathrm{O}_{2}$ column density. In situ measurements made during the Viking mission reported a mixing ratio of $0.13 \%$ at the surface (Owen et al. 1977), consistent with remote observations.

In the 70's, the first measurements of ozone where made with the Mariner probe in the reflected UV spectrum of Mars (Barth et al. 1973 and Wehrbein et al. 1979) and from Earth through the IR airglow of $\mathrm{O}_{2}\left({ }^{1} \Delta\right)$ (Noxon et al. 1976; Traub et al. 1979). They reported a non uniform geographic distribution which is due to surface pressure variation with topography and also to the distribution of water vapor. Indeed, water vapour is distributed according to the temperature and its photolysis by-products efficiently destroy $\mathrm{O}_{3}$. Observations covering the middle latitudes lead to a mean $\mathrm{O}_{3}$ column density of $(4.0 \pm 1.3) \times 10^{15} \mathrm{~cm}^{-2}$ (Espenak et al. 1991). HST observations showed some strong temporal variations linked with the amount of aerosols in the atmosphere (Clancy et al. 1999). $\mathrm{O}_{3}$ column density reached up to $10^{16} \mathrm{~cm}^{-2}$ when the aerosol level was particularly low.

\subsubsection{Icy satellites}

The observation of the UV airglow of the Jupiter's moons Europa and Ganymede revealed the existence of tenuous 
oxygen atmosphere (Hall et al. 1995, 1998). The $\mathrm{O}_{2}$ column densities inferred from these measurements are $(2.4-14) \times 10^{14} \mathrm{~cm}^{-2}$ for Europa and $(1-10) \times 10^{14} \mathrm{~cm}^{-2}$ for Ganymede. These $\mathrm{O}_{2}$ atmospheres are produced by the interaction of charged-particle radiations with water ice, and were predicted by previous studies (Johnson 1990). The icy surfaces of the two satellites are exposed to the strong radiation environment of the inner Jovian magnetosphere. The sputtering of the ice releases atoms and molecules. Hydrogen escapes rapidly and an oxygen atmosphere remains. An unexpected result was the detection, on Ganymede, of the infrared signature of condensed $\mathrm{O}_{2}$ trapped in the water ice and probably also due to the ion bombardment (Spencer et al. 1995). The quantity of $\mathrm{O}_{2}$ within the surface is not well estimated because one does not know whether the oxygen is solid, liquid or trapped in high pressure gas bubbles (Baragiola \& Bahr 1998; Johnson 1999).

$\mathrm{O}_{3}$ was first identified on Ganymede (Noll et al. 1996) and then on Saturn's moons Rhea \& Dione (Noll et al. 1997). The $\mathrm{O}_{3}$ column density estimated is $4.5 \times 10^{16} \mathrm{~cm}^{-2}$ for Ganymede and $(1-6) \times 10^{16} \mathrm{~cm}^{-2}$ for Rhea and Dione. The ozone observed cannot be produced photochemically in the atmosphere because this would imply a ratio $\left[\mathrm{O}_{3}\right] /\left[\mathrm{O}_{2}\right]=10^{-4}-10^{-3}$ which is not consistent with the atmospheric oxygen column density nor with the total density estimated by occultation. The icy satellites exposed to a strong radiation that can be due to a magnetospheric environment seem to build up an $\mathrm{O}_{2-}$ $\mathrm{O}_{3}$ "atmosphere" embedded within the surface (Johnson \& Jesser 1997).

\subsection{Photochemical production of $\mathrm{O}_{2}$ and $\mathrm{O}_{3}$ on terrestrial planets from $\mathrm{CO}_{2}$ and $\mathrm{H}_{2} \mathrm{O}$}

Apart from the Earth, where $\mathrm{O}_{2}$ is abundant and quasiexclusively produced by living bodies, $\mathrm{O}_{2}$ is also present in small amounts on other bodies of the solar system (see Table 1). The two main processes likely to produce detectable quantities of atmospheric $\mathrm{O}_{2}$ on terrestrial planets in the absence of life are the photodissociation of $\mathrm{CO}_{2}$ and $\mathrm{H}_{2} \mathrm{O}$ by stellar UV photons. $\mathrm{CO}_{2}$ and $\mathrm{H}_{2} \mathrm{O}$ are important constituents of the present or past atmosphere of the terrestrial planets Venus, Earth and Mars (see below).

In the atmospheres of Venus and Mars, the photolysis of $\mathrm{CO}_{2}$ is a source of atomic $\mathrm{O}$. The 3 -bodies reaction which rebuilds $\mathrm{CO}_{2}$ is:

$$
\left\{\begin{array}{l}
\mathrm{CO}+\mathrm{O}+\mathrm{M} \longrightarrow \mathrm{CO}_{2}+\mathrm{M} \\
k_{1}(\mathrm{~T})=\underline{3.5} \times 6.5 \times 10^{-33} \exp (-2180 / \mathrm{T}) \mathrm{cm}^{6} \mathrm{~s}^{-1} .
\end{array}\right.
$$

It is much slower than the reaction that forms molecular oxygen:

$$
\left\{\begin{array}{l}
\mathrm{O}+\mathrm{O}+\mathrm{M} \longrightarrow \mathrm{O}_{2}+\mathrm{M} \\
k_{2}(\mathrm{~T})=\underline{3.6} \times 8.6 \times 10^{-28} \mathrm{~T}^{-2} \mathrm{~cm}^{6} \mathrm{~s}^{-1}
\end{array}\right.
$$

(Yung \& Demore 1999, except for the underlined coefficients which account for the nature of the third body $\left(\mathrm{M}=\mathrm{CO}_{2}\right)$ : Warnatz 1984; Tsang 6 Warnatz 1986.)
The ratio $k_{2} / k_{1}$ is in the range $\left[6 \times 10^{4}-2 \times 10^{5}\right]$ in the stratosphere of Venus and $\left[2 \times 10^{5}-10^{7}\right]$ in the atmosphere of Mars. In both cases the presence of photochemically produced $\mathrm{O}_{2}$ is expected. Photochemistry can account for the small quantities of $\mathrm{O}_{2}$ and $/$ or $\mathrm{O}_{3}$ detected in the atmosphere Mars as modelled below (5.1.1).

\subsection{Sources of abiotic oxygen: $\mathrm{CO}_{2}$ and $\mathrm{H}_{2} \mathrm{O}$ on present and past terrestrial planets}

In all terrestrial planets, the history of $\mathrm{CO}_{2}$ and $\mathrm{H}_{2} \mathrm{O}$ are closely related. The composition of their early atmospheres favored by current theories is "neutral" or weakly reducing: $\mathrm{CO}_{2}-\mathrm{H}_{2} \mathrm{O}-\mathrm{N}_{2}$ or $\mathrm{CO}-\mathrm{H}_{2} \mathrm{O}-\mathrm{N}_{2}$ (Kasting 1993) with possible low levels of methane due to a highly reducing upper mantle (Pavlov et al. 2000). This composition is very different from the reducing atmospheres $\left(\mathrm{NH}_{3}, \mathrm{CH}_{4}\right.$, $\mathrm{H}_{2}, \ldots$ ) used in former planetary models as well as in most of the Miller-type laboratory experiments simulating the production of organic compounds in the atmosphere.

\subsection{1. $\mathrm{CO}_{2}$ and $\mathrm{H}_{2} \mathrm{O}$ on Earth}

$\mathrm{CO}_{2}$ is only a minor constituent of present day Earth atmosphere $(0.03 \%$ or 0.3 mbar). Besides very recent human activity, the main phenomena affecting the $\mathrm{CO}_{2}$ content are its release by volcanoes and its precipitation as carbonates in the ocean, partly by microorganisms. Precipitated carbonates are recycled to the mantle through plate tectonics. On the early Earth, several arguments point toward a much larger abundance. The estimated amounts of $\mathrm{CO}_{2}$ trapped in the mantle and the crust are respectively equivalent to 150 and 60 bars (Zhang \& Zindler 1993). The latter reservoir is mainly made of carbonates; their formation requires the presence of liquid water, emerging lands (continents) and calcium-rich rocks. In these conditions the weathering dissolves calcium ions and leads to the formation of $\mathrm{CaCO}_{3}$. All these factors - life, water, continents, calcium salts (the early mantle was rich in sodium rather than calcium salts) - were absent or less favourable at the beginning of Earth history, suggesting a much lower rate of $\mathrm{CO}_{2}$ precipitation as carbonates. On the other hand, mantle outgasing is thought to have been more efficient, releasing either volatiles from late accretion (chondritic or cometary material, Dauphas et al. 2000), especially $\mathrm{CO}_{2}, \mathrm{H}_{2} \mathrm{O}$ and $\mathrm{CO}$, or recycling the first carbonates through juvenile plate tectonics. These arguments point to a higher $\mathrm{CO}_{2}$ content of the early Earth's atmosphere. However the reader should consult the recent work of Zahnle \& Sleep (2001) about the evolution of carbon reservoirs where they estimate that atmospheric $\mathrm{CO}_{2}$ was buffered to low levels.

The presence of liquid water on Earth is attested as early as $-4.3 \mathrm{Gyr}$ (Mojzsis et al. 2001) and even -4.4 Gyr (Wilde et al. 2001) as it is required for the formation of the oldests pieces of rocks known: zircon crystals. The oldest sediments are from the Isua Supergroup, Greenland, and 
have been dated 3.8 Gyr BP. Liquid water is another argument for $\mathrm{CO}_{2}$ in the atmosphere, as the presence of an efficient greenhouse gas is required on the Earth to compensate for the lower luminosity of the young Sun (faint young Sun paradox, Sagan \& Mullen 1972; Kasting et al. 1984), and $\mathrm{CO}_{2}$ is the most likely candidate before gases of biogenic origin, like $\mathrm{CH}_{4}$ and $\mathrm{O}_{3}$, could play a role. However, it should be mentioned that $\mathrm{CH}_{4}$ might have been a prebiotic component of the atmospheres (Galimov 2000) with a significant climatic role (Pavlov et al. 2000). It has been proposed that the system atmospheric $\mathrm{CO}_{2}$ /liquid water is self regulating on the Earth (Walker et al. 1981). A decrease in $\mathrm{CO}_{2}$ lowers the temperature, so that freezing of water occurs and inhibits the dissolution of $\mathrm{CO}_{2}$ in ocean water and the weathering of rocks by rain, whereas $\mathrm{CO}_{2}$ is still released by volcanoes. This mechanism insure a minimum $P_{\mathrm{CO}_{2}}$ value; it should also limit $P_{\mathrm{CO}_{2}}$ towards high values; because the hot climate induced by a high $\mathrm{CO}_{2}$ content would enhance the water cycles and thus increase the weathering and the removal of atmospheric $\mathrm{CO}_{2}$ into carbonate deposits.

Data to constrain $P_{\mathrm{CO}_{2}}$ and $P_{\mathrm{H}_{2} \mathrm{O}}$ through Earth history are scarce. The minimum $P_{\mathrm{CO}_{2}}$ required to maintain water liquid before 4 Gyr is about 200 mbar (Kasting 1993). On the other hand, the absence of $\mathrm{FeCO}_{3}$ (siderite) $2.8 \mathrm{Gyr}$ ago indicates $P_{\mathrm{CO}_{2}}<15$ mbar (Rye et al. 1995). The decrease of $\mathrm{P}_{\mathrm{CO}_{2}}$ may have paralleled the growth of the continental crust. The partial water pressure $P_{\mathrm{H}_{2} \mathrm{O}}$ is very difficult to guess, as it is severely affected by the (unknown) shape of the thermal vertical profile. For a profile similar to the contemporary profile, ground $P_{\mathrm{H}_{2} \mathrm{O}}$ is between 1 and 40 mbar according to the season.

\subsection{2. $\mathrm{CO}_{2}$ and $\mathrm{H}_{2} \mathrm{O}$ on Mars and Venus}

Today water is quasi absent from martian atmosphere (a mean value of $3 \mu \mathrm{m}$-precipitable, equivalent to a column density of $10^{19} \mathrm{~cm}^{-2}$ and a constant mixing ratio of $\left.5 \times 10^{-5}\right)$. This is however sufficient to make Mars atmosphere a "humid" atmosphere from the point of view of photochemistry (catalytic role of $\mathrm{OH}$ radicals, see below).

There are several indications of liquid water on early Mars, 3.5-4 Gyr ago (Carr 1983), which implies its presence in the atmosphere at that time. Geological formations similar to terrestrial river beds, as well as the erosion of the older craters bear testimony of a warmer and more humid climate in the past. A part of this water would now be trapped in polar caps and permafrost (Carr 1986) whereas a fraction was lost due to $\mathrm{H}$ escape (as indicated by the $\mathrm{D} / \mathrm{H}$ ratio, Bjoraker et al. 1989; see also Kass \& Yung 1999).

On Mars $\mathrm{CO}_{2}$ is now the dominant atmospheric species $(95.3 \%)$ of the tenuous (6 mbar) atmosphere. If $\mathrm{CO}_{2}$ is the main greenhouse gas, 2 bar of $\mathrm{CO}_{2}$ would be necessary to maintain liquid water at present, and 5 at the time of the faint early Sun - if one forgets the difficult correction for $\mathrm{CO}_{2}$ cloud formation above 350 mbar
(Forget \& Pierrehumbert 1997). The $\mathrm{CO}_{2}$ content is indeed supposed to have been much larger in the past (Kahn 1985; Pollack et al. 1987; Hoffman 2000). Water is now absent from the atmosphere of Venus, but it may have been present earlier and removed by a runaway greenhouse effect (Rasool \& De Bergh 1970; Kasting 1988). $\mathrm{CO}_{2}$ is thought to have been always present, even if not always as high as its today's value of 90 bars of $\mathrm{CO}_{2}$.

Thus both Mars and Venus may have produced photochemically some $\mathrm{O}_{2}$ and $\mathrm{O}_{3}$ in the past.

\subsection{Interaction of $\mathrm{CO}_{2}$ and $\mathrm{H}_{2} \mathrm{O}$ photochemistry}

The 150 photochemical and chemical reactions included in our photochemical model are listed in Selsis (2000b). The most important reactions for abiotic production of $\mathrm{O}_{2}$ are:

\begin{tabular}{|c|c|c|}
\hline \multicolumn{3}{|c|}{ Oxygen production } \\
\hline (1) $4\left(\mathrm{H}_{2} \mathrm{O}+\mathrm{h} \nu\right.$ & $\longrightarrow$ & $\mathrm{OH}+\mathrm{H})$ \\
\hline (2) $2(\mathrm{OH}+\mathrm{OH}$ & $\longrightarrow$ & $\left.\mathrm{H}_{2} \mathrm{O}+\mathrm{O}\right)$ \\
\hline (3) $\mathrm{O}+\mathrm{O}$ & $\longrightarrow$ & $\mathrm{O}_{2}$ \\
\hline (4) H escape & & \\
\hline $2 \mathrm{H}_{2} \mathrm{O}$ & $\longrightarrow$ & $\mathrm{O}_{2}+(4 \mathrm{H})$ \\
\hline (5) $2\left(\mathrm{CO}_{2}+\mathrm{h} \nu\right.$ & $\longrightarrow$ & $\mathrm{CO}+\mathrm{O})$ \\
\hline (6) $\mathrm{O}+\mathrm{O}$ & $\longrightarrow$ & $\mathrm{O}_{2}$ \\
\hline $2 \mathrm{CO}_{2}$ & $\longrightarrow$ & $2 \mathrm{CO}+\mathrm{O}_{2}$ \\
\hline
\end{tabular}

\begin{tabular}{lll}
\multicolumn{3}{c}{ Oxygen loss } \\
(7) $\mathrm{CO}+\mathrm{OH}$ & $\longrightarrow$ & $\mathrm{CO}_{2}+\mathrm{H}$ \\
$(8) \mathrm{H}+\mathrm{O}_{2}+\mathrm{M}$ & $\longrightarrow$ & $\mathrm{HO}_{2}+\mathrm{M}$ \\
$(9) \mathrm{O}+\mathrm{HO}_{2}$ & $\longrightarrow$ & $\mathrm{O}_{2}+\mathrm{OH}$ \\
\hline $\mathbf{C O}+\mathbf{O}$ & $\longrightarrow$ & $\mathbf{C O}_{2}$
\end{tabular}

These processes are strongly coupled. First, the efficiency of $\mathrm{O}_{2}$ production from $\mathrm{H}_{2} \mathrm{O}$ photodissociation decreases with increasing $\mathrm{CO}_{2}$ abundances, as $\mathrm{CO}_{2}$ absorbs UV photons in the same wavelength range as $\mathrm{H}_{2} \mathrm{O}$ (Fig. 2). Note also from the same figure that photochemical $\mathrm{O}_{2}$ production is to some extent self-regulating, as the photons responsible for $\mathrm{H}_{2} \mathrm{O}$ and $\mathrm{CO}_{2}$ photodissociation can also dissociate $\mathrm{O}_{2}$. Second, in the presence of $\mathrm{HO}_{x}$ radicals $\left(\mathrm{H}, \mathrm{OH}, \mathrm{HO}_{2}\right)$ produced by $\mathrm{H}_{2} \mathrm{O}$ photolysis, catalytic cycles (such as reactions 7, 8 and 9) recombine $\mathrm{O}$ and $\mathrm{CO}$ into $\mathrm{CO}_{2}$, competing with reaction 3 . This recycling into $\mathrm{CO}_{2}$ requires very low abundances of $\mathrm{HO}_{x}$ radicals since they are not consumed in the chemical schemes. Moreover, Yung \& Demore (1999) pointed out a photochemical regulation that keep the sinks for $\mathrm{H}$ and $\mathrm{O}$ in a 2:1 ratio, preventing $\mathrm{O}_{2}$ (and also $\mathrm{H}_{2}$ ) from accumulating. This involves a chemical cycle that couples $\mathrm{CO}_{2}$ and $\mathrm{H}_{2} \mathrm{O}$ photochemistry. Thus the $\mathrm{O}_{2}$ production will be more efficient either in a $\mathrm{CO}_{2}$ dominated atmosphere with very little or no water, or in a humid atmosphere poor in $\mathrm{CO}_{2}$, which are the cases we have considered. 


\section{Model}

A full description of the new model used can be found in Selsis (2000b). We briefly summarize below the main characteristics and new developments contained, and give the references for the basic physical and astronomical input data used.

We have developed two new tools to handle respectively one-dimensional time-dependent photochemistry and radiative transfer in planetary atmospheres. The photochemical code, called PHOEBE (PHOtochemistry for ExoBiology and Exoplanets), produces from initial atmospheric conditions and for a given stellar spectrum the abundances for each chemical species as function of altitude and time. The other code, LWT (Long Wavelengths Transmissions) computes the resultant average infrared spectrum of the planet, as well as the local radiative heating and cooling atmospheric rates.

\subsection{The photochemical model PHOEBE}

The photochemical model extends previous modelling codes developed by the Bordeaux Planetology Group (Titan: Toublanc et al. 1995; Neptune: Dobrijevic \& Parisot 1998; Jupiter: Le Flochmoen 1997; Saturn and Uranus: Ollivier et al. 2000a and b). The following basic physical phenomena are included: photodissociation, 2 and 3 bodies chemical reactions, transfer of the stellar photons (absorption and diffusion), vertical transport of the molecules (by both molecular and eddy diffusion), condensation/evaporation phenomena.

The transfer of UV light has been improved with higher resolution data (now $1 \mathrm{~nm}$, formerly $5 \mathrm{~nm}$ ) for both the solar spectrum and the cross sections. Solar data are from the SUSIM instrument (Floyd et al. 1998). The dependence of absorption and photodissociation crosssections and branching ratios with temperature are now included when they are known. Multiple diffusion is no longer handled through Monte-Carlo methods but through the Isaksen et al. (1977) method. This method gives good results for Rayleigh diffusion, and the speed increase allows us to solve the radiative transfer for each integration step. This method is however less precise than Monte-Carlo methods when applied to Mie scattering by aerosols.

New chemical species have been included, mainly NOx compounds (and chlorine compounds for checks on modern terrestrial atmosphere). There are now 37 species and 150 reactions in our database. For 3-body reactions, we have included an empirical efficiency coefficient, depending on the nature of the third body.

\subsection{The radiative transfer code $L W T$}

In parallel to PHOEBE, we have developed another code for the computation of the radiative properties of the atmosphere in the infrared. This code, called LWT (for Long Wavelength Transmission) provides the radiative cooling and heating rates at each altitude, as well as the average IR spectra of the planet. It follows closely in its structure the MODTRAN code (Berk et al. 1989), covering the spectral interval 1 to $20000 \mathrm{~cm}^{-1}$, with a resolution of $1 \mathrm{~cm}^{-1}$, and for any atmospheric temperature. It includes $\mathrm{CO}_{2}-\mathrm{CO}_{2}$ collision-induced absorption when known (see Selsis 2000b, for a discussion). LWT also permits to reconstruct the thermal profile in radiativeconvective equilibrium with a given chemical composition of the atmosphere. This temperature retrieval includes radiative and chemical heating (obtained from PHOEBE), long wavelength heating and cooling, convective adjustments. The resulting equilibrium is not a local equilibrium, as it couples all the layers in the atmosphere through Curtis matrices (see Coakley 1977). In order to calculate the photochemichal and thermal equilibrium one should use PHOEBE and LWT in an iterative process (see Sect. 5.1.2 and Fig. 4)

\subsection{Validation of the codes}

The PHOEBE code has been applied to the terrestrial and martian atmospheres in order to compare its results with observations and other models. Mean thermal and ozone terrestrial profiles are well reproduced with constant irradiation mode as shown in Fig. 1. In the upper atmosphere, above $70 \mathrm{~km}$, the steady-state profiles computed with a constant irradiation, are quite different from the averaged observations that mix day and night profiles. PHOEBE was also used with a time-dependant irradiation; the results for this day/night mode are consistent with diurnal variations of mesospheric ozone $(>50 \mathrm{~km})$ as observed by a micro-wave instrument (Lezeaux 1999). The code reproduces well the behavior of $\mathrm{O}_{3}$ during the day, validating the modelling at altitudes up to about $90 \mathrm{~km}$.

Simulations of the martian atmosphere, comparisons with observations and previous models have been described at length by Selsis (2000b). Some of these discussions are resumed in part 5.1.1.

\section{Simulations and results}

We present successively our results on the humid $\mathrm{CO}_{2}$ dominated, dry $\mathrm{CO}_{2}$-dominated and water-rich atmospheres. For each atmospheric case under study, we give its description in terms of parameters of the model, the past or present Solar System situation it may correspond to, and/or its theoretical interest for the "maximization" of the false positive detection risk with Darwin. The results are then presented, compared with other existing observational or theoretical work, and their effective significance for the false positive problem is analyzed. The robustness of the results to model changes is explored in more details for case A. An overview of all cases is summarized in Table 3. 

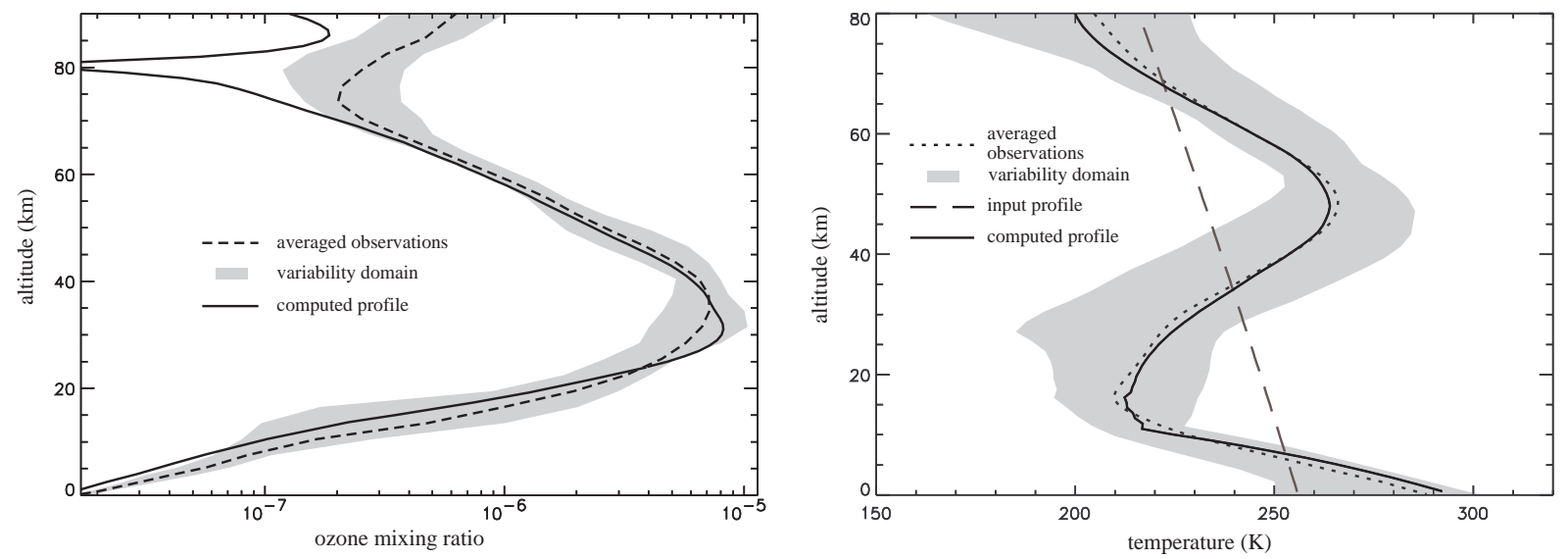

Fig. 1. Model results for the present Earth's atmosphere: thermal a) and $\mathrm{O}_{3} \mathbf{b}$ ) profiles. These profiles (solid lines) are computed for a constant mean irradiation. They are compared with a yearly average (dashed lines) from the CIRA database (Rees et al. 1990). This database contains monthly averaged profiles for $10 \mathrm{deg}$ latitude bands; the grey area represents the envelop of all these CIRA profiles. The model fits very well the $\mathrm{O}_{3}$ data at most altitudes; the discrepancy above $70 \mathrm{~km}$ is apparent and due to night/day effects (see text, part 4.3). In graph b), the long-dashed line shows the initial temperature profile used for the photochemical and temperature retrieval modelling; after 3 iterations, the PHOEBE profile (solid line) matches very well the observations.

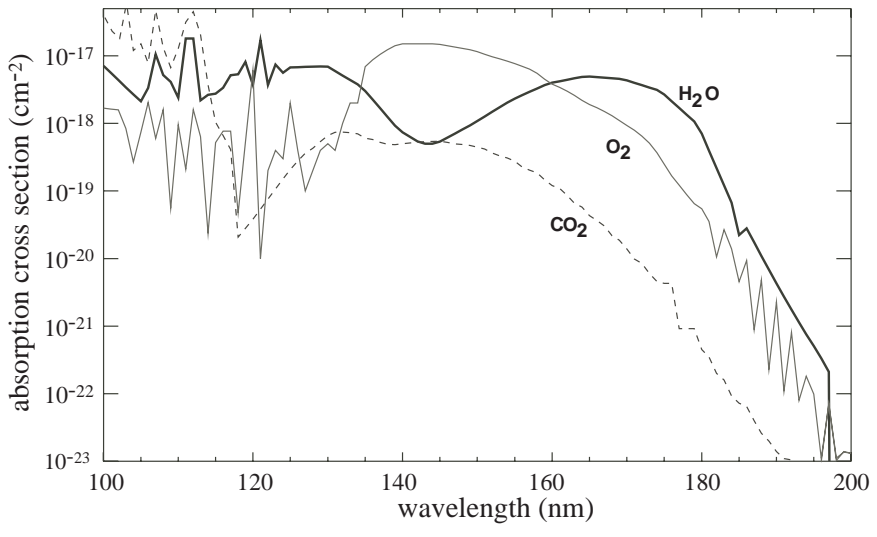

Fig. 2. Photodissociation cross sections of $\mathrm{H}_{2} \mathrm{O}, \mathrm{CO}_{2}$ and $\mathrm{O}_{2}$.

\subsection{Humid $\mathrm{CO}_{2}$-dominated atmospheres}

We made four different runs. In all of them water vapor abundances were close to the saturation value. The $\mathrm{CO}_{2}$ pressure increased from 6 mbar (case A) to 1 bar (case B) and 3.2 bar (case $\mathrm{C})$; the last case $\mathrm{D}\left(P_{\mathrm{CO}_{2}}=\right.$ 0.2 bar) "maximizes" the risk of a false positive detection of life. In cases $\mathrm{A}$ and $\mathrm{B}$, the atmosphere was pure $\mathrm{CO}_{2}$, whereas cases $\mathrm{C}$ and D included also 0.8 bar of $\mathrm{N}_{2}$, leading respectively to total pressures $P_{\text {tot }}$ of 4 bar and 1 bar. Beside their representativity of humid $\mathrm{CO}_{2}$-dominated atmospheres, these cases were also studied for themselves as representing A) Mars today; B) a possible terraforming (McKay et al. 1991) or ancient state of Mars; C and D) two plausible stages of the early Earth atmosphere; see Selsis (2000b) for more details.

\subsubsection{Case $\mathrm{A}\left(P_{\text {tot }}=P_{\mathrm{CO}_{2}}=6 \mathrm{mbar}\right)$}

All input parameters for this run correspond to presentday Mars; the set of values is the same as used by
Nair et al. (1994). The mean chemical atmospheric composition is that determined from Viking data (Owen et al. 1997): $95.3 \% \mathrm{CO}_{2}, 2.7 \% \mathrm{~N}_{2}, 1.6 \%$ Ar. We adopted the thermal profile recommended by Seiff (1982) up to $100 \mathrm{~km}$ and the one by Nair between 100 and $220 \mathrm{~km}$. Groundlevel humidity has been adjusted to obtain a column density of $3.1 \mu \mathrm{m}$ precipitable water, which is within the range observed on Mars (Clancy et al. 1992); a run with $8.2 \mu \mathrm{m}$ has also been performed. The law for the turbulent diffusion coefficient $K$ as a function of altitude has been fitted from the data compiled by Krasnopolsky (1993). The variation of the surface albedo with $\lambda$ has been parametrized according to Lindner (1985). When included, $\mathrm{H}$ and $\mathrm{H}_{2}$ escape and $\mathrm{O}_{2}$ sink on the surface are supposed to correspond to the stationary state (loss of $2 \mathrm{H}$ atoms for one $\mathrm{O}$ atom), as result e.g. of the regulation mechanism proposed by Yung \& DeMore (1999).

Simulations were first conducted for a basic set of conditions: constant solar flux, $3.1 \mu \mathrm{m}-\mathrm{pr} \mathrm{H}_{2} \mathrm{O}, \mathrm{H}$ and $\mathrm{O}$ escape. The set of chemical reactions and reaction rates has been optimized, leading to a database we called "MARS" (Selsis 2000b), different from the JPL97 database (DeMore et al. 1997) by taking into account the specific role of $\mathrm{CO}_{2}$ as a third body in the association reactions. The production of $\mathrm{O}_{2}$ and $\mathrm{O}_{3}$ through photolysis is shown in Fig. 3. After a growth for 100000 yr the abundances reach a constant value close to present day values for Mars, which are respectively about $10^{-3}$ and $10^{-8}$ in mixing ratio.

The effects of suppressing the $\mathrm{O}$ and $\mathrm{H}$ escape, increasing the humidity, changing the chemistry database, and night/day alternance versus mean solar flux have been also investigated; the results are summarized in Table 3 . The observations (see Table 1) are best reproduced by cases using the optimized "MARS" chemical database, and including $\mathrm{H}$ and $\mathrm{O}$ escape. This shows that standard chemical 

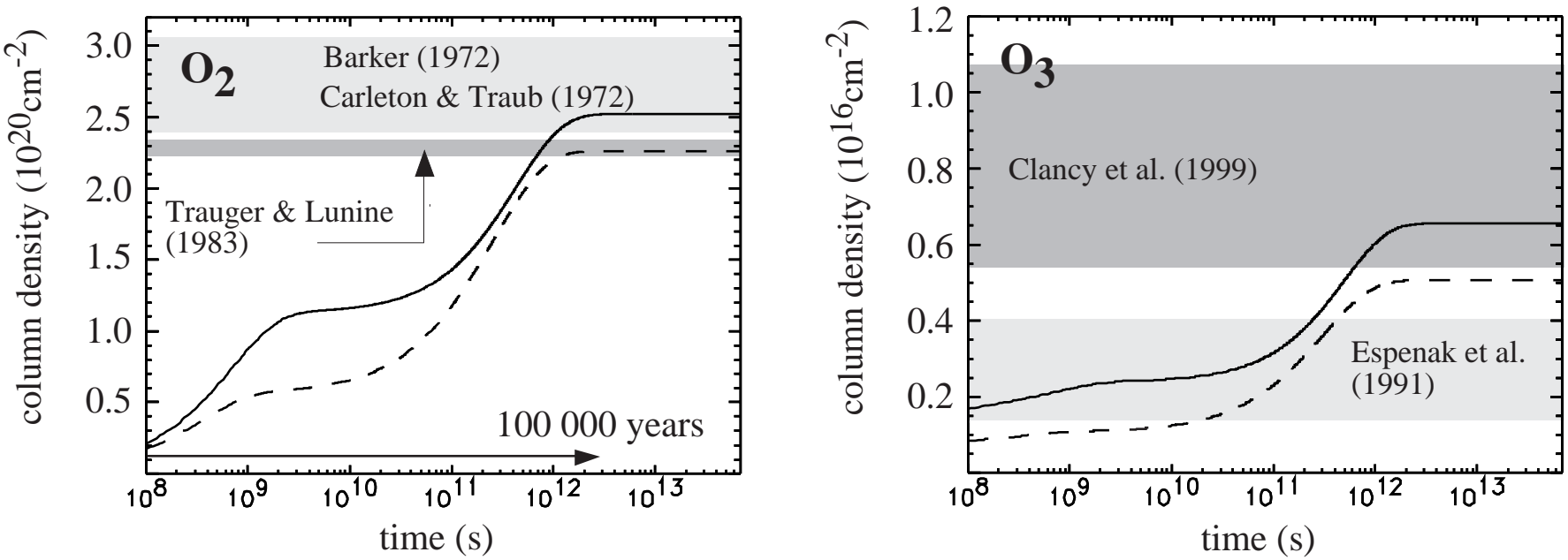

Fig. 3. Evolution of the $\mathrm{O}_{2}$ and $\mathrm{O}_{3}$ column densities as a function of time for a humid $\mathrm{CO}_{2}$ dominated Mars-like atmosphere at low pressure $\left(P_{\mathrm{CO}_{2}}=6 \mathrm{mbar}\right)$. The $\mathrm{H}_{2} \mathrm{O}$ column density corresponds to $3.1 \mu \mathrm{m}$ precipitable water (solid line); a more humid atmosphere $(8.2 \mu \mathrm{m}-\mathrm{pr})$ is also shown (dotted line). Note that more water results in less $\mathrm{O}_{2}$ and $\mathrm{O}_{3}$ (see text). A steady state is reached after $100000 \mathrm{yr}$. The grey areas represent the abundance range deduced from observations for these two compounds nowadays.

databases (like the JPL97 database, developed for terrestrial applications) need to be adapted according to the nature of the background gas(es) (e.g. carbon dioxide).

The $\mathrm{O}_{2}$ abundance changes but $\mathrm{O}_{2}$ remains a minor component $(<0.3 \%)$ : we notice that even the twofold increase in $\mathrm{O}_{2}$ from case A-1a to case A-1c results in only an $\mathrm{O}_{3}$ increase of $25 \%$.

Note that more water results in less $\mathrm{O}_{2}$ and $\mathrm{O}_{3}$, illustrating the mechanism alluded to above (Sect. 3.4): the increase of radicals $\mathrm{H}, \mathrm{OH}$ and $\mathrm{HO}_{2}$ diminishes the $\mathrm{O}_{2}$ production (by catalyzing the $\mathrm{CO}$ and $\mathrm{O}$ recombination to $\mathrm{CO}_{2}$ ) and efficiently destroys $\mathrm{O}_{3}$. We also tested whether the mean abundances of the various compounds are affected when taking into account the diurnal variation of the insolation. As our model is time dependent, we can simulate the evolution with small time steps (10 min maximum). This mode of simulation however does not allow long integration times. Starting from the steady state found in case A we note that the mean $\mathrm{O}_{2}$ content is slightly sensitive to the day/night alternance and evolves from the initial state: an increase of $0.2 \%$ is seen for 250 days. Longer term effects have still to be checked.

We conclude that in a Martian-like, low pressure, pure $\mathrm{CO}_{2}$ atmosphere, the abiotic production of $\mathrm{O}_{2}$ and $\mathrm{O}_{3}$ is marginal $\left(2 \times 10^{-3}\right.$ and $10^{-7}$ at most $)$; this result is robust with respect to uncertainties in the modelling process. Such a low $\mathrm{O}_{3}$ content would not show up in the IR spectrum taken by Darwin, which will not be able to detect an absorption or emission feature less intense than about one fifth of the terrestrial $\mathrm{O}_{3}$ band (Léger, private communication).

\subsubsection{Case $\mathrm{B}\left(P_{\mathrm{tot}}=P_{\mathrm{CO}_{2}}=1 \mathrm{bar}\right)$}

How does the previous result change for a denser humid $\mathrm{CO}_{2}$ atmosphere? Let us consider now a 1 bar atmosphere
Table 2. Case A (present Mars). This Table shows the dependence of the results for $\mathrm{O}_{2}$ and $\mathrm{O}_{3}$ on some of the input parameters. The observations (see Table 1) are best reproduced by cases A-1a and A-2, which use the optimized "MARS" chemical database, and include $\mathrm{H}$ and $\mathrm{O}$ escape.

\begin{tabular}{l|ccccc}
\hline \hline & A-1a & A-1b & A-1c & A-1d & A-2 \\
\hline$N_{\mathrm{H} 2 \mathrm{O}}(\mu \mathrm{m}-\mathrm{pr})$ & 3.1 & 3.1 & 3.1 & 3.1 & 8.2 \\
Chemistry & MARS & MARS & JPL & JPL & MARS \\
Escape & yes & no & yes & no & yes \\
$\times\left(\mathrm{O}_{2}\right)\left(\times 10^{-3}\right)$ & 1.1 & 0.5 & 2.4 & 0.5 & 1.0 \\
$N_{\mathrm{O}_{2}}\left(10^{20} \mathrm{~cm}^{-2}\right)$ & 2.5 & 1.1 & 5.3 & 1.0 & 2.3 \\
$N_{\mathrm{O}_{3}}\left(10^{15} \mathrm{~cm}^{-2}\right)$ & 6.5 & 2.5 & 8.0 & 0.5 & 5.0 \\
\hline
\end{tabular}

made of $\mathrm{CO}_{2}$, with water present. This case can be seen as the Martian atmosphere some time in the past (see Sect. 3.3.2). It may also represent an eventual future of the planet, according to the "terraforming" scenario proposed by McKay et al. (1991), where the introduction of an efficient greenhouse gas (e.g. CFC) in small quantities initiates an increase in the temperature and leads to the sublimation of $\mathrm{CO}_{2}$ and $\mathrm{H}_{2} \mathrm{O}$, which themselves generate a runaway greenhouse effect liberating more of those gases. In a 1 bar atmosphere, a partial pressure of 1 mbar for $\mathrm{O}_{2}$ is the minimum for growing plants (McKay et al. 1991).

Such an atmosphere has already been modelled by Chassefière \& Rosenqvist (1995a), who obtained a partial pressure $P_{\mathrm{O}_{2}}$ of 1 mbar, assuming a "terrestrial thermal profile without stratosphere", to take into account the a priori absence of heating by $\mathrm{O}_{3}$. But, as noted by these authors, the water vapor profile critically influences the $\mathrm{O}_{2}$ production, and this profile itself relies heavily on the thermal profile. 
Table 3. Model parameters and results for each case. The parameters were chosen to favour, under realistic conditions, an $\mathrm{O}_{2} / \mathrm{O}_{3}$ abiotic enrichment. However none of the surveyed cases presented the triple signature of Earth-like oxygenic photosynthesis: no false positive case. The weak triple signature in case $\mathrm{G}$ appears in an unlikely extreme situation (see text). Notes: (1) Adjusted to obtain the column density measured on Mars (i.e. 3.1 and 8.2 microns precipitable of $\left.\mathrm{H}_{2} \mathrm{O}\right)$. (2) Surface humidity: $H_{\text {surf }}=1 \%$, so that $X_{\mathrm{H}_{2} \mathrm{O}}$ (surface) $/ X_{\text {saturated }}=0.01$. (3) In units of present mean solar flux at Earth distance. Case A, B: present solar flux at Mars distance; cases C, D: solar flux at $1 \mathrm{AU} 4.2$ Gy ago according to standard evolutionnary models; Cases E, F: flux set to have a mean surface temperature of about $300 \mathrm{~K}$ (a false positive detection has to be in the habitable zone). (4) Results for no NO flux nor $\mathrm{O}_{2}$ sink. For the effect of these, see text. (6) Computation of the thermal profile was done only for the initial state of the atmosphere, no iterations were made after photochemical calculations. (5) Left column: results with the initial fixed thermal profile; right column results with the computed thermal profile. (7) The range of values given for $\mathrm{O}_{2}$ and $\mathrm{O}_{3}$ in cases $\mathrm{C}$ and $\mathrm{D}$ accounts for the presence or not of NO production by lightnings (Navarro-Gonzalez et al. 1998). The others influences we have tested $\left(\mathrm{O}_{2}\right.$ sinks and volcanic emission of reducing species) are not included here because they make the abundances of $\mathrm{O}_{2}$ and $\mathrm{O}_{3}$ completely negligeable compare to detectable levels. (8) The triple signature required for Darwin to suspect a biologic activity consists in the simultaneous presence of mid-IR bands of all three species $\mathrm{O}_{3}, \mathrm{H}_{2} \mathrm{O}$ and $\mathrm{CO}_{2}$. This takes into account the resolution and sensitivity of the instrument.

\begin{tabular}{|c|c|c|c|c|c|c|c|c|}
\hline \multirow[b]{2}{*}{ Cases } & \multicolumn{5}{|c|}{$\mathrm{CO}_{2}$ humid } & \multicolumn{2}{|c|}{$\mathrm{CO}_{2} \mathrm{dry}$} & \multirow{2}{*}{$\begin{array}{l}\mathrm{H}_{2} \mathrm{O} \text { influx } \\
\mathrm{G}\end{array}$} \\
\hline & $\mathrm{A}$ & \multicolumn{2}{|c|}{ B } & $\mathrm{C}$ & $\mathrm{D}$ & $\mathrm{E}$ & $\mathrm{F}$ & \\
\hline$P_{\text {tot }}(\mathrm{mbar}) / P_{\mathrm{CO}_{2}}(\mathrm{mbar})$ & $6 / 6$ & \multicolumn{2}{|c|}{$1000 / 1000$} & $4000 / 3200$ & $1000 / 200$ & $4000 / 4000$ & $1000 / 50$ & $1000 /$ traces \\
\hline$X_{\mathrm{CO} 2}$ & 0.957 & \multicolumn{2}{|c|}{1} & 0.8 & 0.2 & 1 & 0.05 & $3 \times 10^{-4}$ \\
\hline $\mathrm{H}_{2} \mathrm{O}$ & $N_{\mathrm{H}_{2} \mathrm{O}}(\mathbf{1})-3.1 / 8.2$ & \multicolumn{2}{|c|}{$H_{\text {surf }}(2)-1 \%$} & $H_{\text {surf }} 100 \%$ & $H_{\text {surf }} 100 \%$ & no & no & constant input \\
\hline$P_{\mathrm{N}_{2}}($ mbar $)$ & 0.16 & \multicolumn{2}{|c|}{0} & 800 & 800 & 0 & 950 & 1000 \\
\hline solar flux (3) & 0.43 & \multicolumn{2}{|c|}{0.43} & 0.73 & 0.73 & 0.5 & 0.7 & 1 \\
\hline gravity & Mars & \multicolumn{2}{|c|}{ Mars } & Earth & Earth & Earth & Earth & Earth \\
\hline $\mathrm{O}_{2}$ surface losses & no & \multicolumn{2}{|c|}{ no } & no $(4)$ & no $(4)$ & no & no & yes, $<\mathrm{H}_{2}$ losses \\
\hline thermal profile & observed & arbitrary $\left(\mathrm{B}_{1}\right)$ & computed $\left(\mathrm{B}_{2}\right)$ & educated guess & educated guess & \multicolumn{2}{|c|}{ computed (6) } & computed \\
\hline $\begin{array}{l}\text { influences } \\
\text { tested }\end{array}$ & $\begin{array}{l}\text { chemistry, day/night } \\
\text { H/O escape, moisture }\end{array}$ & \multicolumn{2}{|c|}{ thermal profile } & $\begin{array}{l}\mathrm{O}_{2} \text { loss, } \\
\text { volcanism }\end{array}$ & $\begin{array}{l}\mathrm{O}_{2} \text { loss, } \\
\text { volcanism }\end{array}$ & & & high stellar UV \\
\hline$P_{\mathrm{O}_{2}}($ mbar $)$ & $6 \times 10^{-3}$ & $0.5(5)$ & $20(5)$ & {$[0.4-4](7)$} & {$[0.01-0.1](7)$} & 27 & 3.5 & decrease \\
\hline $\mathrm{O}_{2}$ column density $\left(\mathrm{cm}^{-2}\right)$ & $2.5 \times 10^{20}$ & $1.3 \times 10^{22}$ & $8.8 \times 10^{23}$ & {$\left[10^{22}-10^{23}\right]$} & {$\left[10^{20}-10^{21}\right]$} & $2.7 \times 10^{24}$ & $9 \times 10^{22}$ & \\
\hline $\mathrm{O}_{2}$ mixing ratio & $10^{-3}$ & $5 \times 10^{-4}$ & 0.02 & {$\left[10^{-4}-10^{-3}\right]$} & {$\left[10^{-5}-10^{-4}\right]$} & $2.7 \%$ & $0.35 \%$ & $<1 \%$ \\
\hline $\mathrm{O}_{3}$ column density $\left(\mathrm{cm}^{-2}\right)$ & $6.5 \times 10^{15}$ & $5 \times 10^{17}$ & $1.8 \times 10^{19}$ & $<10^{17}$ & $<10^{16}$ & $3.4 \times 10^{18}$ & $1.7 \times 10^{18}$ & \\
\hline $\mathrm{O}_{3}$ mixing ratio & $\approx 10^{-8}$ & $2 \times 10^{-8}$ & $5 \times 10^{-7}$ & $<10^{-9}$ & $<10^{-10}$ & $3 \times 10^{-8}$ & $7 \times 10^{-8}$ & $<10^{-7}$ \\
\hline $\begin{array}{l}\text { comments } \\
\text { \& Figures }\end{array}$ & $\begin{array}{l}\text { Mars today } \\
3\end{array}$ & $\begin{array}{c}\text { early or te } \\
\text { Mars }\end{array}$ & $\begin{array}{l}\text { rraformed } \\
4-5-6\end{array}$ & $\begin{array}{l}\text { early Earth I } \\
7\end{array}$ & $\begin{array}{l}\text { early Earth II } \\
8\end{array}$ & $9-10$ & $11-12$ & $\begin{array}{l}\text { comet or hydrated } \\
\text { IDPs infall / } 13\end{array}$ \\
\hline Triple signature? (8) & no & $\mathrm{n}$ & $\mathrm{o}$ & no & no & no & no & marginal \\
\hline
\end{tabular}




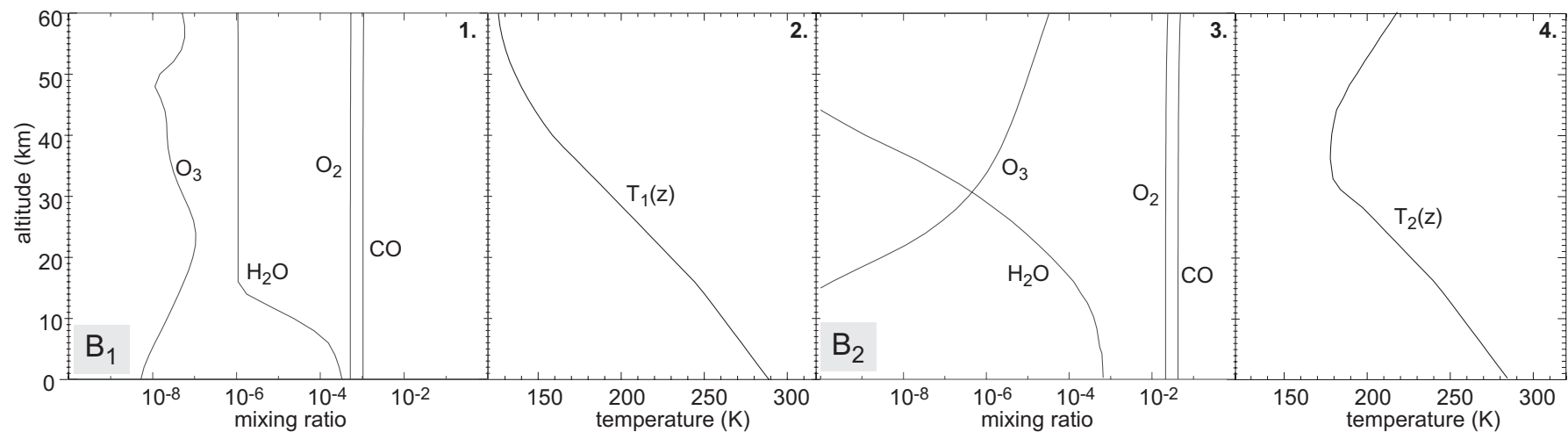

Fig. 4. Photochemistry in a 1 bar $\mathrm{CO}_{2}$ atmosphere (case B). This graphs show the iterative procedure used to calculate the thermal and chemical profiles. The first step consists in calculating the chemical evolution using an initial guess of the thermal profile (it was taken from Rosenqvist \& Chassefière 1995) and corresponds to a modified terrestrial profile, isothermal above the tropopause). Once a steady state reached, a new thermal profile, $T_{1}$ is computed in radiative-convective equilibrium with this composition (step 2). Photochemical computation and temperature retrieval are repeated once again (steps 3 and 4 ). This iterative procedure should be proceeded until reaching stable conditions but this highly time-consuming task was not completed. Anyway, the photochemical states called $\mathrm{B}_{2}$ and $\mathrm{B}_{1}$ can be shown respectively as an upper limit and an extreme lower limit for the $\mathrm{O}_{2}$ and $\mathrm{O}_{3}$ contents. Indeed, the cold trap that leads to a water vapor depletion above $30-40 \mathrm{~km}$ will still be efficient with the thermal profile $T_{1}: \mathrm{H}_{2} \mathrm{O}$ abondance in the stratosphere will increase, but not above $10^{-7}$. This will lower slightly the $\mathrm{O}_{2}-\mathrm{O}_{3}$ production but then, a lower $\mathrm{O}_{3}$ abundance would lead to a colder stratosphere and to less water vapor. From this result we suggest an equilibrium state close to $\mathrm{B}_{2}$ with a temperature profile between $T_{1}$ and $T_{2}$. For the resulting infrared emission, see Fig. 6 .

The different steps of our modelling of this case B are shown in Fig. 4. We started the simulation with the same thermal profile as Rosenqvist and Chassefière and obtained a first photochemical equilibrium (step 1). This case $\left(\mathrm{B}_{1}\right)$ reproduces approximately the case studied by these authors, with a partial pressure $P_{\mathrm{O}_{2}} \approx 0.5 \mathrm{mbar}^{3}$. Then we computed the temperature profile ( $T_{1}$ in Fig. 4$)$ in radiative-convective equilibrium with this chemical composition (step 2). This new profile displays a strong decrease in temperature with increasing altitudes due to the low level of ozone and the absence of stratospheric warming. We let then the chemistry evolve from the state $\mathrm{B}_{1}$ to a new steady state $\mathrm{B}_{2}$ (step 3 ). The $\mathrm{O}_{2}$ abundance is considerably higher (40 times), with $P_{\mathrm{O}_{2}} \approx 20 \mathrm{mbar}$ leading to a "super ozone layer", which is compared to the terrestrial case in Fig. 5. This ozone layer, in turn, heats the upper atmosphere, giving the next thermal profile $T_{2}$ (step 4). As the thermal effects are not directly coupled with the photochemical evolution, one should proceed with such iterations until reaching a final self-consistent state. This very time consuming task has not been undertaken in the present work. However, from these calculations, we can show that the final solution is bracketed allowing the estimation of the false positive risk. The thermal structure $T_{2}$ still provides a cold trap, limiting the vertical transport of $\mathrm{H}_{2} \mathrm{O}$, and the level of water vapor in the hot stratosphere cannot exceed $10^{-8}-10^{-7}$. This is enough to diminish slightly the production of $\mathrm{O}_{2}$

3 The factor 2 difference may be attributed to the role of $\mathrm{CO}_{2}$ in the association reactions which is taken into account in our model. Indeed, in the case A (current Mars) the introduction of this effect leads to a decrease of the $\mathrm{O}_{2}$ column density from $5.3 \times 10^{20}$ to $2.5 \times 10^{20} \mathrm{~cm}^{-2}$.

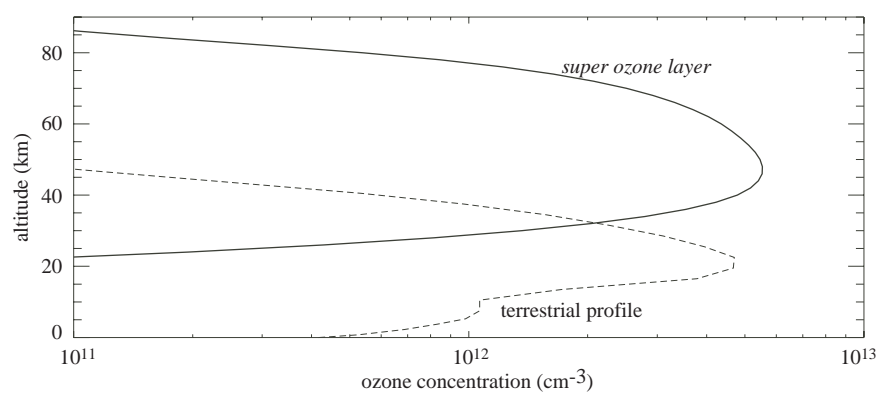

Fig. 5. Super ozone layer produced in a 1-bar humid $\mathrm{CO}_{2}$ atmosphere (solid line, case $\mathrm{B}_{2}$ ). Terrestrial ozone is shown for comparison (dashed line).

and $\mathrm{O}_{3}$ which, in turn, lowers the stratospheric warming and moisture, providing a negative feedback. Hence, the chemical equilibrium cannot differ much from state $B_{2}$. This one and the thermal profile $T_{2}$ can be seen as upper limits respectively for the $\mathrm{O}_{2}$ and $\mathrm{O}_{3}$ contents and the temperature.

The existence of an ozone layer as dense as on Earth, or even denser, is thus not necessarily a by-product of biological activity. But does this super ozone layer lead to an observable $\mathrm{O}_{3}$ IR band for Darwin, and hence to a "false positive"? The infrared emission calculated for the chemical composition $\mathrm{B}_{2}$ is shown in Fig. 6. Synthetic spectra were computed for both the thermal structure $T_{1}$ and $T_{2}$, in order to display the $\mathrm{O}_{3}$ feature for both extreme cases. Despite the relatively high abundance of $\mathrm{O}_{2}$ and $\mathrm{O}_{3}$, the latter molecule will not be detected in this case with Darwin: the large quantity of $\mathrm{CO}_{2}$ present in the atmosphere completely masks its signature (see Fig. 6). The sensitivity and resolution required to reveal the $\mathrm{O}_{3}$ 


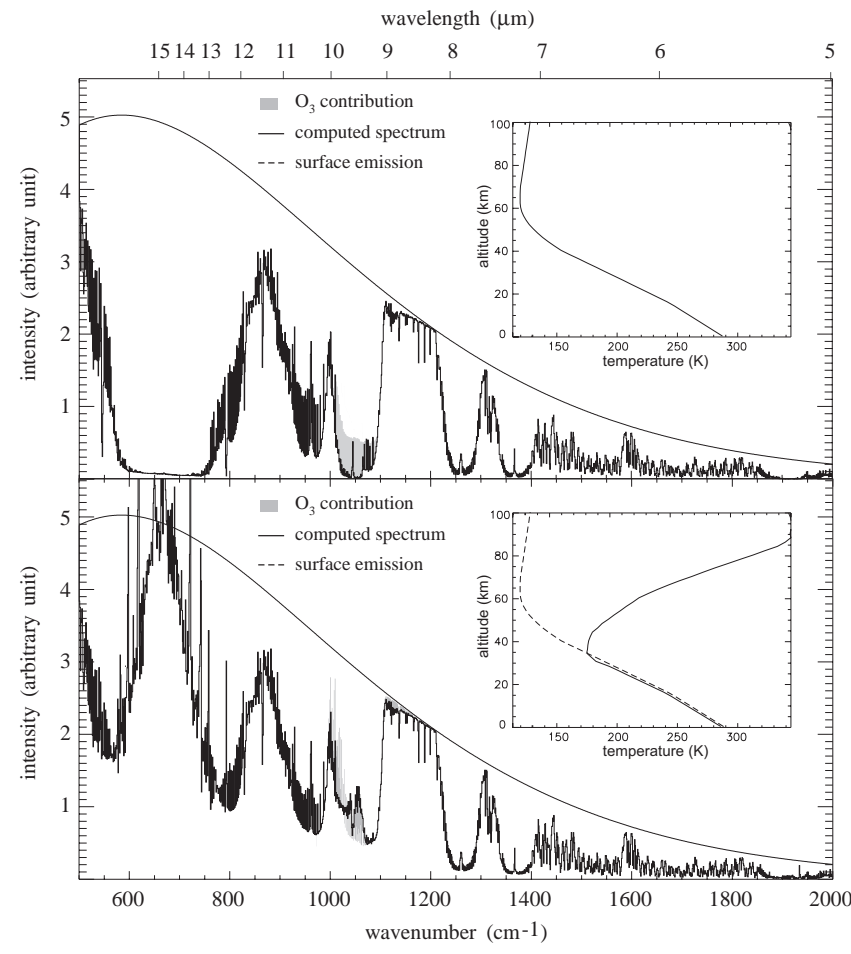

Fig. 6. IR emission of an 1 bar $\mathrm{CO}_{2}$ humid atmosphere. This case B may for example be representative of an early Mars, or a terraformed Mars. Synthetic spectra have been computed for the maximum $\mathrm{O}_{3}$ content and the two extreme temperature profiles. The shaded grey area indicates the ozone feature, which is embedded within $\mathrm{CO}_{2}$ bands. At Darwin resolution and signal-to-noise ratio $(\Delta \lambda \sim 0.5 \mu \mathrm{m}, S N R<10$, Volonte et al. 2000), the presence of $\mathrm{O}_{3}$ cannot be inferred, for any temperature profiles contained between these ones. There is no false postive risk even at higher resolution as the high $\mathrm{CO}_{2}$ pressure features (within the $9-11 \mu \mathrm{m}$ and also $7-8 \mu \mathrm{m}$ ranges) will warn about the possible abiotic origin of $\mathrm{O}_{2}$ and $\mathrm{O}_{3}$.

feature is far beyond the capability of the first generation of instruments that will be dedicated to the spectroscopic study of extrasolar planets. Moreover, in the further perspective of high performance instruments able to resolve this weak $\mathrm{O}_{3}$ contribution from $\mathrm{CO}_{2}$ features, the presence of high pressure $\mathrm{CO}_{2}$ bands would warn the observer about the possible abiotic origin of this signature.

In this case $\mathrm{B}$, the non-detectability of $\mathrm{O}_{3}$ eliminates any "false positive" risk for the Darwin strategy based on the $\mathrm{O}_{3}$ criterium; it however points out the opposite risk of false negative (see Sect. 6.2.3).

\subsubsection{Case $\mathrm{C}\left(P_{\text {tot }}=4\right.$ bars, $P_{\mathrm{CO}_{2}}=3200 \mathrm{mbar}$, $P_{\mathrm{N}_{2}}=800$ mbar)}

This case and the following one are $\mathrm{CO}_{2}$-rich humid atmospheres, with the same $\mathrm{N}_{2}$ content as in the present Earth atmosphere, but high $\left(P_{\mathrm{CO}_{2}}=0.2\right.$ bar $)$ to very high $\left(P_{\mathrm{CO}_{2}}=3.2\right.$ bar $) \mathrm{CO}_{2}$ abundance. These neutral atmospheres are possible states of the early Earth atmosphere (Case $\mathrm{C}$ has been investigated as such by Navarro-Gonzalez et al. 1998).

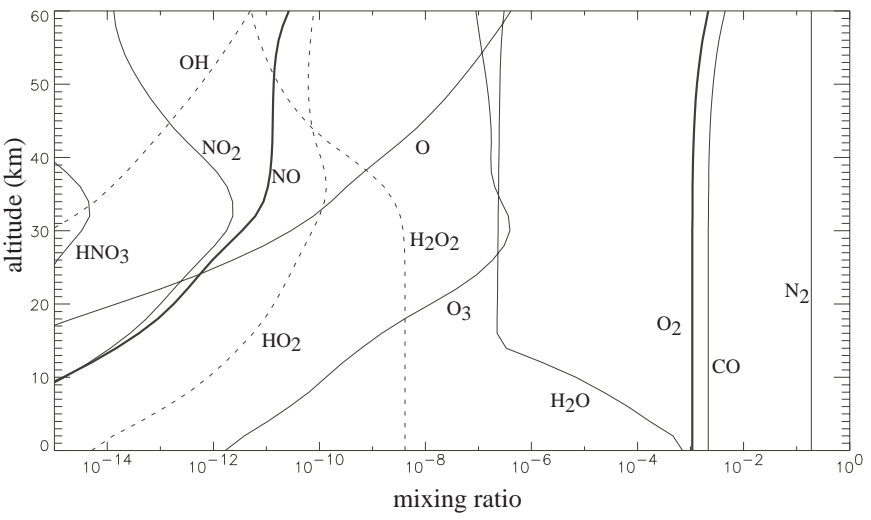

Fig. 7. Case $\mathrm{C}$ : dense $\mathrm{CO}_{2}$-dominated humid atmosphere (4 bars, $80 \% \mathrm{CO}_{2}, 20 \% \mathrm{~N}_{2}$ ). This atmosphere contains as much $\mathrm{N}_{2}$ as present day Earth atmosphere and may represent a very early stage of the early Earth atmophere. Chemical relative abundances are ploted as a function of altitude. No NO flux nor $\mathrm{O}_{2}$ surface sink included (see text).

We first discuss the most extreme case (C). The temperature profile is taken similar to the present one on Earth but for the stratospheric ozone heating which is suppressed. The solar flux is $73 \%$ of the present one (Gough 1981), which corresponds to 4.2 Gyr BP according to standard evolution models of the Sun; the surface temperature remains high due to the greenhouse effect of $\mathrm{CO}_{2}$. The relative humidity at surface level is assumed to be $100 \%$.

After about $10^{5}$ yr a chemical steady state is reached (Fig. 7), with a mixing ratio of photochemically-produced $\mathrm{O}_{2}$ of about $10^{-3}\left(P_{\mathrm{O}_{2}} \approx 4\right.$ mbar $)$ and only $10^{-7}$ for $\mathrm{O}_{3}$.

To provide a better representation of the early Earth, simulations have been conducted for both cases C and D where a gas production linked to volcanic activity and a $\mathrm{O}_{2}$ sink by oxydation of surface rocks are included; these simulations also address the problem of the $\mathrm{NO} / \mathrm{O}_{2}$ ratio, crucial for some prebiotic reaction (Commeyras et al. 2002). The volcanic gas sources include NO, produced by lightnings in volcanic plumes, and reducing species $\left(\mathrm{H}_{2}\right.$, $\mathrm{CO}$ or $\mathrm{CH}_{4}$ ) released in the case of a more reducing upper mantle. In all cases the volcanic gases decrease the oxygen and ozone contents. We conclude that in the high $P_{\mathrm{CO}_{2}}$ humid atmosphere of case $\mathrm{C}$ no ozone IR feature would thus be seen by Darwin, due to the low ozone content, and the masking by $\mathrm{CO}_{2}$ lines.

\subsubsection{Case D $\left(P_{\text {tot }}=1\right.$ bars, $P_{\mathrm{CO}_{2}}=200 \mathrm{mbar}$, $P_{\mathrm{N}_{2}}=800$ mbar $)$}

The previous case $\mathrm{C}$ may not correspond to a long-lasting stage of the planet evolution in the presence of abundant liquid water and continental crust, as weathering will efficiently pump atmospheric $\mathrm{CO}_{2}$ into carbonates (Pollack et al. 1987; Sleep \& Zahnle 2001). Furthermore, on the Earth itself geological evidence suggests a maximum $P_{\mathrm{CO}_{2}}$ of $\approx 40$ mbar since 2.8 Gyr BP (Rye et al. 1995); note however that we have no constraints from rocks on $P_{\mathrm{CO}_{2}}$ 


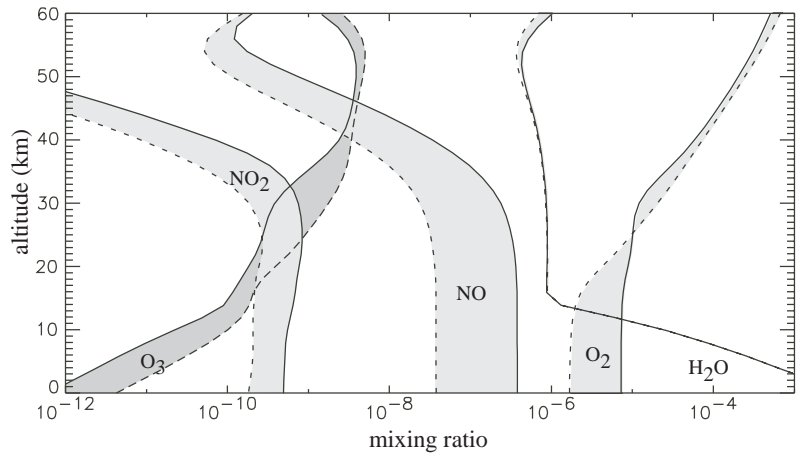

Fig. 8. Case D: medium density $\mathrm{CO}_{2}$-dominated humid atmosphere (1 bar, $20 \% \mathrm{CO}_{2}, 80 \% \mathrm{~N}_{2}$ ). This atmosphere also contains as much $\mathrm{N}_{2}$ as present day Earth atmosphere, but seems a more likely representation of the early Earth atmosphere. Chemical relative abundances are ploted as a function of altitude. The grey area between solid and dashed lines indicates the variability of the profiles with or without oxygen surface sink and with low or high NO production (see text).

for earlier times. The minimum $\mathrm{CO}_{2}$ pressure needed for maintaining the temperature above the water freezing point at early times ( $\approx 4 \mathrm{Gyr}$ ago) is 200 mbar in the absence of methane (Pavlov et al. 2000). We thus conducted a simulation for this value, which is more likely to represent a substantial fraction of the evolution of the Earth's early atmosphere than case $\mathrm{C}$.

The vertical profiles of some species, at steady state, are shown in Fig. 8. The $\mathrm{O}_{2}$ production appears less efficient than in the previous case, with a relative abundance between $10^{-6}$ (ground) and $10^{-3}$ (at $\approx 60 \mathrm{~km}$ ). The ground level value for $\mathrm{O}_{2}$ decreases even further if a $\mathrm{NO}$ volcanic source and $\mathrm{O}_{2}$ surface sink are included.

As in case $\mathrm{C}$, we conclude that no infrared $\mathrm{O}_{3}$ feature will be seen by Darwin. Thus dense humid $\mathrm{CO}_{2}$-rich atmosphere have a low photochemical production of $\mathrm{O}_{2}$ and will not display any "false positive" $\mathrm{O}_{3}$ signature for Darwin.

\subsection{Dry $\mathrm{CO}_{2}$ atmospheres}

In the humid $\mathrm{CO}_{2}$-rich atmospheres studied above, $\mathrm{HO}_{x}$ radicals produced by $\mathrm{H}_{2} \mathrm{O}$ photolysis limit the production of $\mathrm{O}_{2}$. What happens in a dry $\mathrm{CO}_{2}$ atmosphere? Nair et al. (1994) have used their photochemical model of Mars to study the equilibrium state of such an atmosphere when water is absent. They obtain a mixing ratio of $3.9 \times 10^{-2}$ for $\mathrm{O}_{2}$ (and $7.7 \times 10^{-2}$ for $\mathrm{CO}$ ), with $\mathrm{CO}_{2}$ remaining the main atmospheric constituents. This contradicts Atreya \& Gu (1994), who estimate that $\mathrm{CO}_{2}$ should be fully converted to $\mathrm{CO}$ and $\mathrm{O}_{2}$ in less than $6000 \mathrm{yr}$. An equilibrium model like that used by Nair et al. seems inappropriate to handle the problem, as the physical conditions are strongly modified during the conversion of $\mathrm{CO}_{2}$ to $\mathrm{CO}$ and $\mathrm{O}_{2}$ : increase of the density (by a factor 1.5 when the conversion is complete), modification of the hydrostatic equilibrium, surface warming and mid atmosphere cooling due to $\mathrm{CO}_{2}$. We study here a 4 bar $\mathrm{CO}_{2}$ atmosphere (case E), which

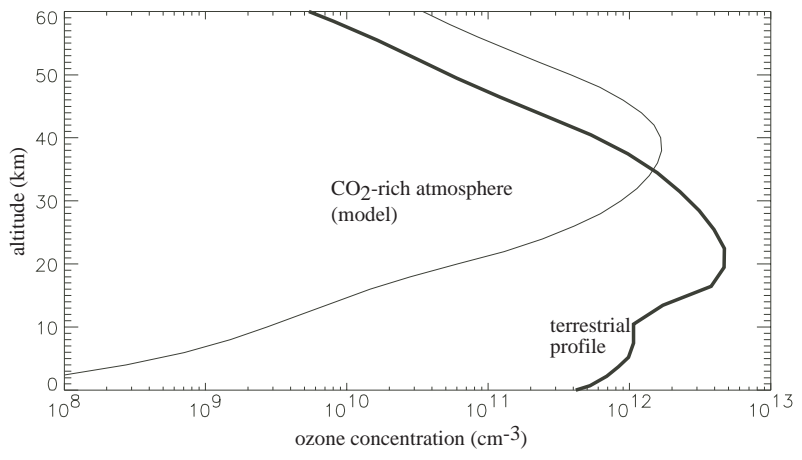

Fig. 9. Case E: ozone layer produced in a 4 bar dry pure $\mathrm{CO}_{2}$ atmosphere; the terrestrial profile is shown for reference (heavy solid line).

leads to a large $\mathrm{O}_{2}$ and $\mathrm{O}_{3}$ content, and a 50 mbar $\mathrm{CO}_{2}$ atmosphere (case $\mathrm{F}$ ), which is a compromise between the $\mathrm{O}_{2}$ production and the detectability of the $\mathrm{O}_{3}$ IR bands.

\subsubsection{Case $\mathrm{E}: 4$ bar pure $\mathrm{CO}_{2}$ atmosphere}

We consider a pure $\mathrm{CO}_{2}$ very dense atmosphere with Earth's gravity. To handle the evolution of the physical parameters, we make a stepwise computation, readjusting the physical parameters after each step. We made simulations up to $300000 \mathrm{yr}$ only due to computation time limitations. After $300000 \mathrm{yr}, \mathrm{O}_{2}$ reaches a level of 2.7\%; this stage is not yet fully stationary, but further $\mathrm{O}_{2}$ evolution appears extremely slow, as $\mathrm{O}_{2}$ absorbs the very same photons which dissociate $\mathrm{CO}_{2}$. It seems thus that $\mathrm{CO}_{2}$ remains the main constituent of such an atmosphere, as predicted, despite its limitations, by the equilibrium model of Nair et al. In Fig. 9 we show the $\mathrm{O}_{3}$ concentration. The upper atmosphere is richer than the Earth's atmosphere; this is due to the absence of the hydrogen compounds responsible for catalytic destruction of $\mathrm{O}_{3}$. The concentration of $\mathrm{O}_{3}$ at low altitude is low: production is limited due to the high $\mathrm{CO}_{2}$ column density which severely limits the number of dissociating $(\lambda<242 \mathrm{~nm})$ photons there, whereas $\mathrm{O}_{3}$ produced at higher altitudes is photodissociated by longer wavelength photons before reaching the lower atmosphere.

The simulated IR Darwin spectrum for this atmosphere is shown in Fig. 10. No $\mathrm{O}_{3}$ signature is present, due to the high $\mathrm{CO}_{2}$ content which masks the $\mathrm{O}_{3}$ lines between 9 and $10 \mu \mathrm{m}$ (900 and $\left.1100 \mathrm{~cm}^{-1}\right)$.

\subsubsection{Case $\mathrm{F}: 1$ bar dry low $\mathrm{CO}_{2}$ (50 mbar or $5 \%$ ) $\mathrm{N}_{2}(95 \%)$ atmosphere}

Now we try to maximize the risk of having an $\mathrm{O}_{3}$ signature in a $\mathrm{CO}_{2}$-rich atmosphere: we consider a case where $P_{\mathrm{CO}_{2}}$ is $\sim 50$ mbar, which is just below the 100 mbar $\mathrm{CO}_{2}$ pressure threshold above which the masking of $\mathrm{O}_{3}$ bands by $\mathrm{CO}_{2}$ takes place, while keeping a high photochemical production of $\mathrm{O}_{2}$, and hence the possibility of an $\mathrm{O}_{3}$ $9.6 \mu \mathrm{m}$ band. The $\mathrm{N}_{2}$ content is $20 \%$ higher than on Earth 


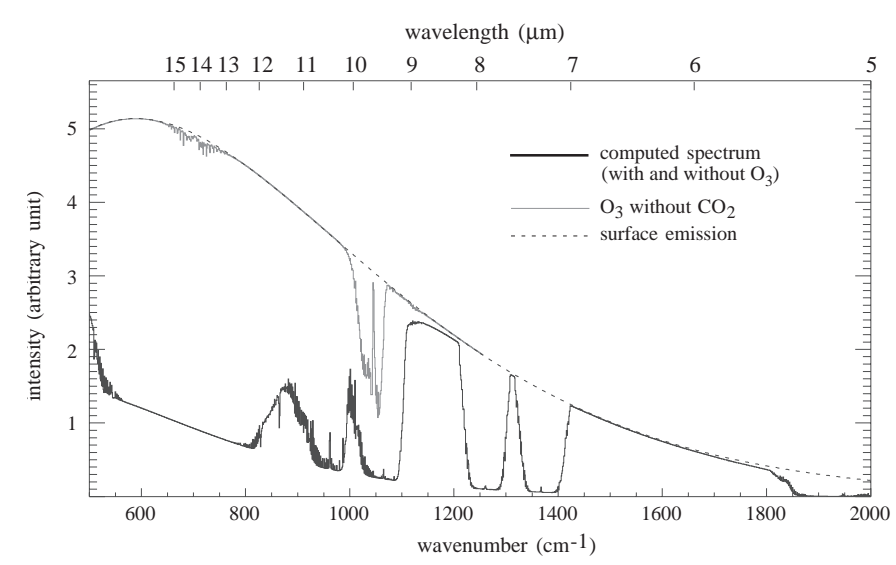

Fig. 10. Case E: IR Darwin spectrum simulated for a 4 bar dry pure $\mathrm{CO}_{2}$ atmosphere. Despite of the important $\mathrm{O}_{3}$ layer (see Fig. 9) the $\mathrm{O}_{3}$ signature is completely masked by $\mathrm{CO}_{2}$ lines between 900 and $1100 \mathrm{~cm}^{-1}$.

just to have a 1 bar atmosphere. The presence of $\mathrm{N}_{2}$ as a background gas simplifies the numerical treatment without significantly affecting the chemistry $\left(\mathrm{N}_{2}\right.$ does not absorb at the wavelengths important for the dissociation of $\mathrm{CO}_{2}$ and $\mathrm{O}_{2}$, nor is chemically active). An equilibrium is reached after 50000 yr; Fig. 11 displays the corresponding abundance profiles.

The partial pressure of photochemically produced $\mathrm{O}_{2}$ reaches 3.5 mbar. If $\mathrm{O}_{2}$ is consumed by surface oxydation processes, the photochemical $\mathrm{O}_{2}$ production must proceed continuously, and the atmosphere needs a constant $\mathrm{CO}_{2}$ supply, e.g. from comets or volcanoes. But, in both cases, other compounds are also injected (water, and in the second case, sulfur and chlorine compounds), both reducing the efficiency of the $\mathrm{O}_{2}$ and $\mathrm{O}_{3}$ accumulation, either by chemical reduction or by catalysing the $\mathrm{CO}$ and $\mathrm{O}_{2}$ recombination to $\mathrm{CO}_{2}$. In the atmosphere of Venus, chlorine and sulfur compounds oxidize $\mathrm{CO}$ to $\mathrm{CO}_{2}$ (e.g. Yung \& DeMore 1999); this explains why, in this $\mathrm{CO}_{2}$-rich atmosphere, the $\mathrm{O}_{2}$ abundance is so low (cf. above, Sect. 3.1.1).

As seen in Fig. 12, the $\mathrm{O}_{3}$ band can only barely be detected in the IR spectrum; only a very good signal to noise and a very precise knowledge of the $\mathrm{CO}_{2}$ abundance and of the thermal profile would allow one to infer the presence of $\mathrm{O}_{3}$ from this spectrum.

\subsection{Case G: Humid atmosphere with permanent water supply}

Water is dissociated into $\mathrm{OH}+\mathrm{H}$ or $\mathrm{O}+\mathrm{H}_{2}$ in the upper atmosphere; as $\mathrm{H}$ and $\mathrm{H}_{2}$ escape, the atmosphere is enriched in oxygen. Such an accumulation however can proceed if, and only if, the $\mathrm{O}_{2}$ consumption (oxydation of rocks, reactions with volcanic gases, ...) is less efficient than hydrogen escape. On Venus, for example, the $\mathrm{H}$ escape on a short time scale may have produced a $\mathrm{O}_{2}$-rich atmosphere, but for a limited time only (Kasting 1988).

To have such a phenomenon for a longer time, one may consider a constant supply of water, for example by a constant influx of comets, or of small ice particles of cometary origin (this case was suggested to us by J. Schneider). Another case of interest is an $\mathrm{H}_{2} \mathrm{O}$-dominated atmosphere with an initial $\mathrm{H}_{2} \mathrm{O}$ reservoir but no permanent influx; such a situation might have occurred e.g. on a warmer early Europa. Case G can be used to set upper limits for the $\mathrm{O}_{2}$ photochemical production in the latter case.

We thus consider here a planet of Earth size and gravity with a humid atmosphere, a constant $\mathrm{H}_{2} \mathrm{O}$ influx, high hydrogen escape rate, low $\mathrm{O}_{2}$ consumption by surface oxidation, 1 bar of $\mathrm{N}_{2}$ and low level of minor species which would act as catalysts of $\mathrm{H}$ and $\mathrm{O}$ recombination to $\mathrm{H}_{2} \mathrm{O}$. We include however $0.03 \%$ of $\mathrm{CO}_{2}$ (its abundance on Earth): without such traces there would not be the "triple $\mathrm{CO}_{2}-\mathrm{H}_{2} \mathrm{O}-\mathrm{O}_{3}$ signature" in Darwin spectra, and hence no "false positive" risk. The $\mathrm{H}_{2} \mathrm{O}$ influx of $10^{10} \mathrm{~cm}^{-2} \mathrm{~s}^{-1}$ is high enough to ensure a very high $\mathrm{H}_{2} \mathrm{O}$ stratospheric abundance of about $10^{-3}$ (as opposed to $10^{-6}$ in the present Earth's stratosphere). Note that this flux is 1000 times higher than the estimated delivery flux required to explain the water vapor observed in the atmosphere of giant planets (Feuchtgruber et al. 1997). Due to the strong $\mathrm{H}_{2} \mathrm{O}$ influx, such an atmosphere leads to specific numerical problems like imposing small time steps. This limits in practice the duration of the numerical integration to $\approx 100$ years, which is low compared to time required to have a significant $\mathrm{O}_{2}$ build up. We tackle the problem in a different way, including in the initial atmosphere a small quantity of $\mathrm{O}_{2}$, and studying its variation with time. We have thus included $1 \% \mathrm{O}_{2}$. For higher contents, UV photons are largely absorbed by $\mathrm{O}_{2}$ and $\mathrm{H}_{2} \mathrm{O}$ is no longer efficiently photodissociated. Our computations show that the $\mathrm{O}_{2}$ content tends to decrease, and thus that $1 \% \mathrm{O}_{2}$ (10 mbar) represents an extreme upper limit of the possible oxygen content of this kind of humid atmosphere. Figure 13 shows the vertical $\mathrm{O}_{3}$ profile (as compared with the terrestrial one). $\mathrm{O}_{3}$ is present with a very low mixing ratio $\left(<10^{-7}\right)$. This is lower than expected from extrapolating from the $20 \% \mathrm{O}_{2}$ standard terrestrial atmosphere to a $1 \% \mathrm{O}_{2}$ following the logarithmic behaviour established by Paetzold (1962) and Léger et al. (1993); this is due to the specific nature of the humid atmosphere under study: the catalytic destruction of $\mathrm{O}_{3}$ by $\mathrm{H}$ and $\mathrm{HO}_{x}$ species is strongly enhanced compared to the Earth.

This catalytic destruction follows these three main cycles:

\begin{tabular}{lll}
$\mathrm{OH}+\mathrm{O}$ & $\longrightarrow$ & $\mathrm{H}+\mathrm{O}_{2}$ \\
$\mathrm{H}+\mathrm{O}_{3}$ & $\longrightarrow$ & $\mathrm{OH}+\mathrm{O}_{2}$ \\
\hline $\mathbf{O}+\mathrm{O}_{3}$ & $\longrightarrow$ & $\mathbf{2 O}_{2}$ \\
& & \\
$\mathrm{OH}+\mathrm{O}_{3}$ & $\longrightarrow$ & $\mathrm{HO}_{2}+\mathrm{O}_{2}$ \\
$\mathrm{HO}_{2}+\mathrm{O}$ & $\longrightarrow$ & $\mathrm{OH}+\mathrm{O}_{2}$ \\
\hline $\mathbf{O}+\mathrm{O}_{3}$ & $\longrightarrow$ & $\mathbf{2 O}_{2}$ \\
& & \\
$\mathrm{OH}+\mathrm{O}_{3}$ & $\longrightarrow$ & $\mathrm{HO}_{2}+\mathrm{O}_{2}$ \\
$\mathrm{HO}_{2}+\mathrm{O}_{3}$ & $\longrightarrow$ & $\mathrm{OH}_{2} \mathrm{O}_{2}$ \\
\hline $\mathbf{2 O}_{3}$ & $\longrightarrow$ & $\mathbf{3 O}_{2}$
\end{tabular}




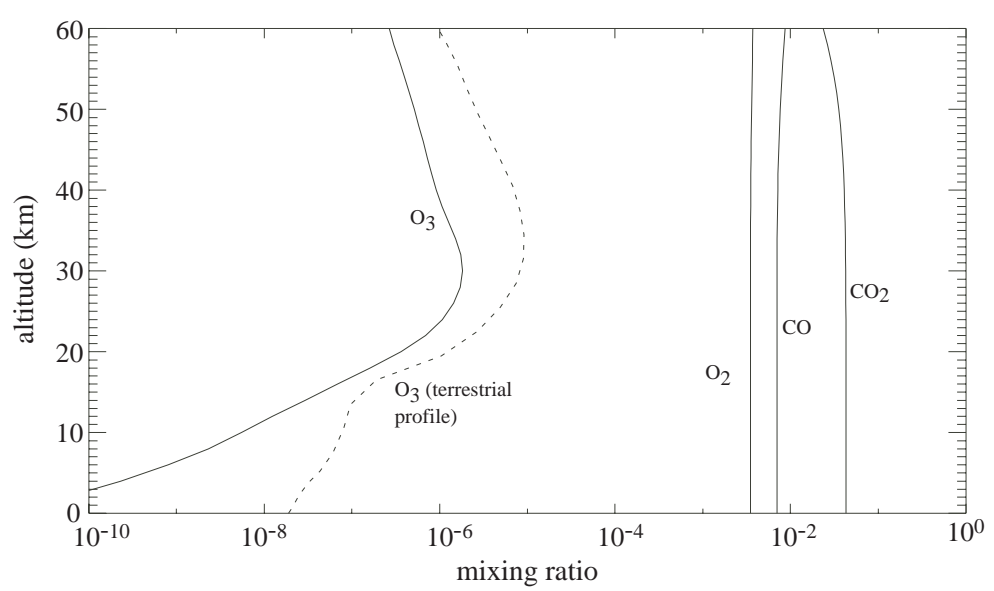

Fig. 11. Case F: steady state computed from an initial dry atmosphere of $95 \% \mathrm{~N}_{2}, 5 \% \mathrm{CO}_{2} . \mathrm{O}_{2}$ mixing ratio reaches $0.3 \%$. The middle atmosphere $\mathrm{O}_{3}$ profile shows the logarithmic dependance of $\mathrm{O}_{3}$ on the $\mathrm{O}_{2}$ content predicted by Léger et al. (1993) but the lower atmosphere is very depleted in $\mathrm{O}_{3}$ as compared to the Earth. The thermal spectrum obtained is shown in Fig. 12 .

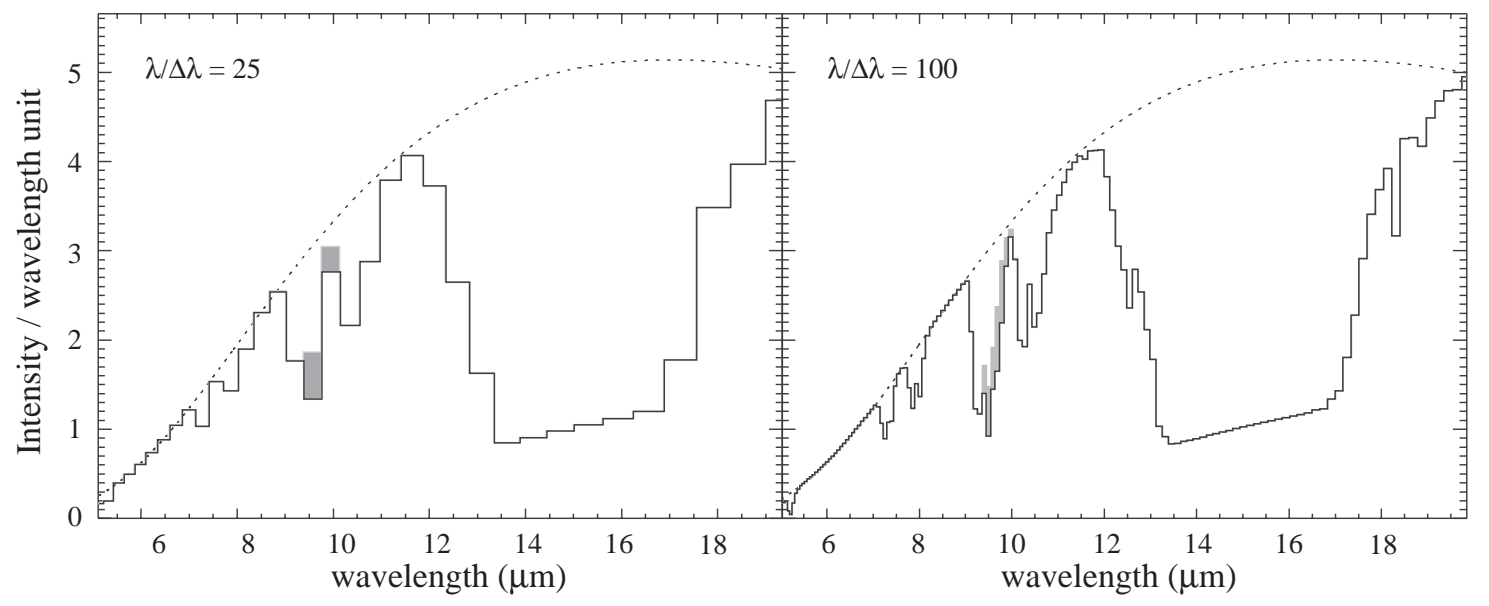

Fig. 12. Case F: IR Darwin spectrum computed for a 1 bar $\mathrm{N}_{2}$ dry atmosphere with $5 \%$ (50 mbar) of $\mathrm{CO}_{2}$. The $9.6 \mu \mathrm{m}$ ozone signature (in grey) is mixed with the $\mathrm{CO}_{2}$ bands at 9 and $11 \mu \mathrm{m}$. Even with the capability to separate the two features this would not be consider as a "false-positive" case because the $\mathrm{O}_{3}-\mathrm{CO}_{2}$ absorption is not associated to an $\mathrm{H}_{2} \mathrm{O}$ signature. The triple criterium is not gathered here.

An efficient production of $\mathrm{O}_{2}$ in a humid atmosphere requires a very high rate of $\mathrm{H}_{2} \mathrm{O}$ photolysis driven by strong UV radiations in the water-rich upper atmosphere. $\mathrm{H}$ and $\mathrm{HO}_{x}$ radicals are then much more abundant and also chemically efficient in a wider range of altitudes. The ozone destruction is then amplified by the very same process that produces $\mathrm{O}_{2}$, even in the absence of the main species responsible for the ozone destruction on Earth: the $\mathrm{NO}_{x}$ (these radicals come from the photolysis of $\mathrm{N}_{2} \mathrm{O}$ which is a by-product of biological activity and therefore are not present in the abiotic cases we considered.) For Darwin nominal $(R=25)$ and improved $(R=100)$ resolutions, there is only a marginal signature of $\mathrm{O}_{3}$ in the IR spectrum (Fig. 14), despite the fact that lower $\mathrm{O}_{3}$ means less warming of the atmosphere, and an enhanced contrast of the absorbing band (Selsis 2000a). Although $\mathrm{CO}_{2}$ and $\mathrm{H}_{2} \mathrm{O}$ bands are present in this spectrum, we consider that, with planned Darwin resolution and sensitivity, the weakness of the $\mathrm{O}_{3}$ band makes extremely low the risk of identifying a humid atmosphere with constant $\mathrm{H}_{2} \mathrm{O}$ influx as a false positive case. Moreover, the necessity of matching, for the planet, the many ad hoc conditions quoted at the beginning of this paragraph makes this risk even more marginal (see discussions, Sect. 6.2.2).

\section{Discussion}

\subsection{Extension to other cases of terrestrial exoplanets}

\subsubsection{Influence of the spectral type of the star}

What would be the impact of changing the stellar spectrum on the photochemical production of $\mathrm{O}_{2}$ and $\mathrm{O}_{3}$ ? The most important parameter is the ratio $R_{\mathrm{uv}}=F_{\mathrm{uv}} / F_{\mathrm{tot}}$ where $F_{\mathrm{uv}}$ is the stellar flux in the UV range important for photochemistry $([100-400] \mathrm{nm})$ and $F_{\text {tot }}$ the total integrated flux. We performed simulations with $R_{\mathrm{uv}}<$ solar $R_{\mathrm{uv}}$ (cooler stars); in all cases they gave a lower $\mathrm{O}_{2}$ and $\mathrm{O}_{3}$ content. We also performed simulations with 


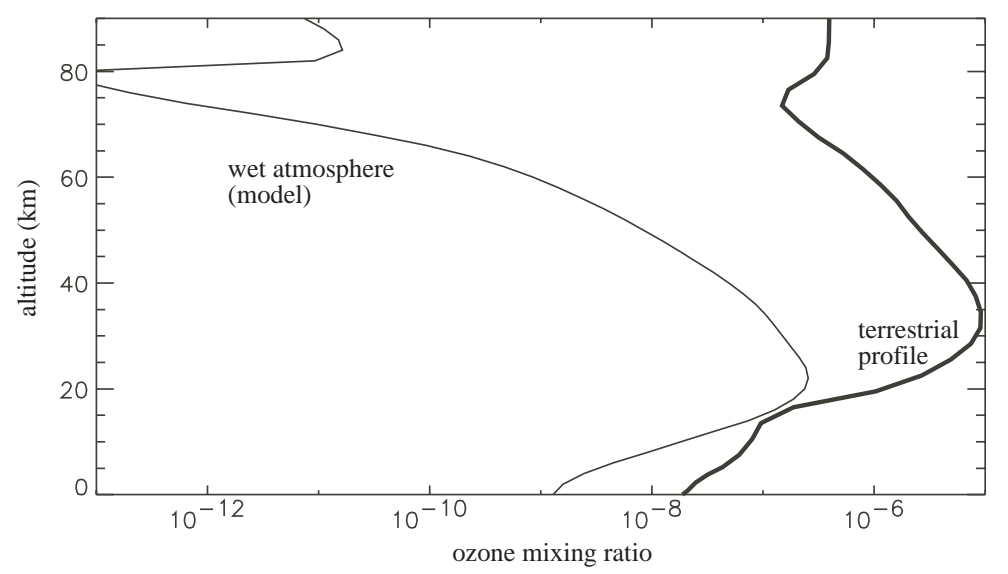

Fig. 13. Case G: ozone layer produced in a humid atmosphere $\left(1\right.$ bar $\left.\mathrm{N}_{2}, 0.1 \% \mathrm{H}_{2} \mathrm{O}\right)$ with constant $\mathrm{H}_{2} \mathrm{O}$ influx and little $\mathrm{CO}_{2}$ $(0.03 \%)$. There is a strong destruction of ozone in the stratosphere catalysed by HOx compounds (whereas in the terrestrial case $\mathrm{NO}_{x}$ and chlorine compounds are the main species responsible for that). The terrestrial profile is shown for reference (heavy solid line).

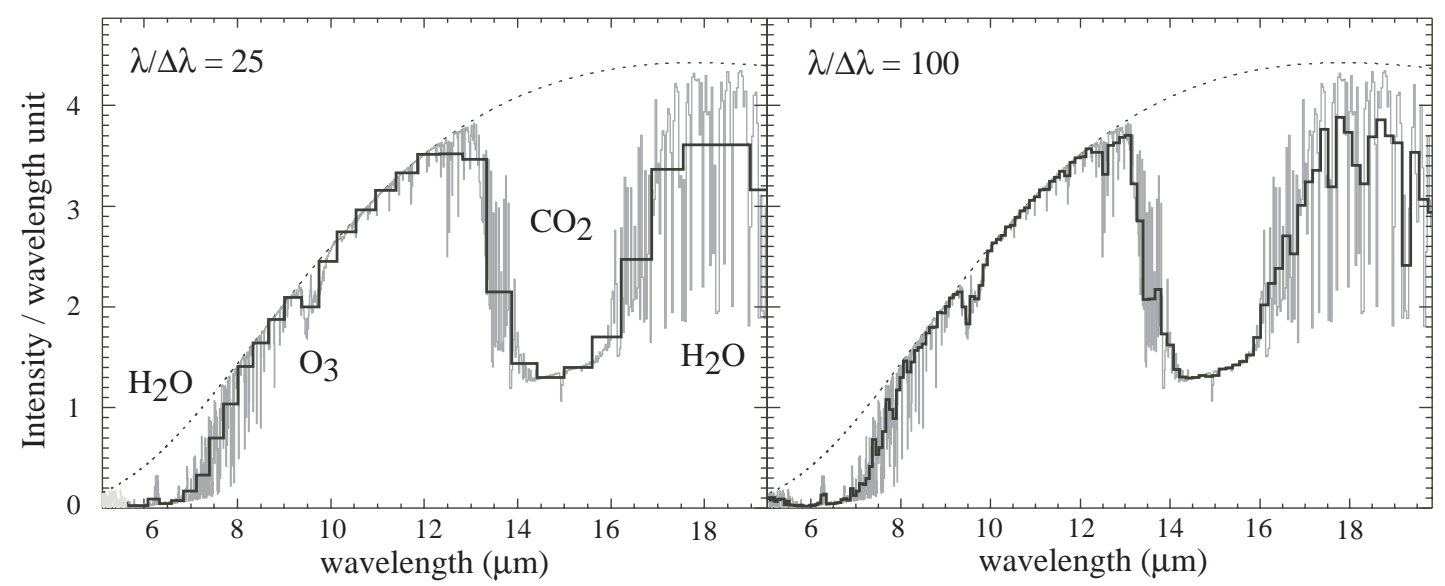

Fig. 14. Case G: IR Darwin spectrum simulated for a humid atmosphere $\left(1\right.$ bar $\left.\mathrm{N}_{2}, 0.1 \% \mathrm{H}_{2} \mathrm{O}\right)$ with constant $\mathrm{H}_{2} \mathrm{O}$ influx and little $\mathrm{CO}_{2}(0.03 \%)$. The $\mathrm{O}_{3}$ line is barely detectable at present $(R=25$, left $)$ and improved $(R=100$, right $)$ Darwin resolution. Despite the presence of $\mathrm{CO}_{2}$ and $\mathrm{H}_{2} \mathrm{O}$ line, the risk to detect such case as a "false positive" is marginal.

$R_{\mathrm{uv}}>$ solar $R_{\mathrm{uv}}$ (hotter or very young stars $^{4}$ ), but only for case $\mathrm{G}\left(\mathrm{O}_{2}\right.$ production from $\mathrm{H}_{2} \mathrm{O}$ photolysis and $\mathrm{H}$ escape), without changing our conclusions.

For other cases with a high $R_{\mathrm{uv}}$, it is difficult to guess what would happen: more UV produces more atomic oxygen, but not necessary more $\mathrm{O}_{2}$ or $\mathrm{O}_{3}$, because these species are also unstable under high UV irradiation. We note however that:

- A possible consequence of higher $R_{\mathrm{uv}}$ would be to produce in case $\mathrm{F}$ an $\mathrm{O}_{3}$ signature with less $\mathrm{CO}_{2}$ $\left(P_{\mathrm{CO}_{2}}<50\right.$ mbar $)$. Then, there would be less $\mathrm{CO}_{2}$ masking and we would see an unambiguous $\mathrm{O}_{3}$ feature.

${ }^{4}$ The case of young stars with high UV (T-Tauri phase) and its impact on inorganic photochemistry has been studied by Canuto et al. (1982). However, this UV/EUV excess cannot interact with the primitive atmosphere because 1) the stellar phase involved is too short $\left(<10^{5} \mathrm{yr}\right.$, Bontemps, private communication); 2) UV excess is produced by dust accreting on the star and the same dust absorbs the UV in the planetary disk.
But anyway, case $\mathrm{F}$ is dry and does not display the $\mathrm{H}_{2} \mathrm{O}$ component of the triple signature required to trace biophotosynthesis;

- Hot stars like F-stars are rarer than solar or less luminous stars and have a shorter life. We showed elsewhere (Selsis 2000a) that the $9.6 \mu \mathrm{m} \mathrm{O}_{3}$ band is not a robust way to detect $\mathrm{O}_{2}$-rich (Earth-like) atmospheres around such hot stars. Indeed, the temperature contrast between the surface and the emitting ozone layer is too low to induce a signature detectable by a Darwin-like instrument.

\subsubsection{The case of reducing early atmospheres}

When exploring the past of the Earth's atmosphere, we concentrated on the scenario favoured nowadays for the primitive atmosphere, i.e. a $\mathrm{CO}_{2}-\mathrm{H}_{2} \mathrm{O}-\mathrm{N}_{2}$ mixture. If one considers the option of a mildly reducing atmosphere (Pavlov et al. 2000; Galimov 2000), the possibilities of photochemically producing a substantial amount of $\mathrm{O}_{2}$ 
are much lower. Namely, reducing gases like $\mathrm{H}_{2}, \mathrm{CH}_{4}$ or $\mathrm{NH}_{3}$ would react with $\mathrm{O}_{2}$ and strongly limit its level (see e.g. Selsis 2002 about the $\mathrm{CH}_{4} / \mathrm{O}_{2}$ competition). Therefore abiotic photochemical production of $\mathrm{O}_{2}$ in reducing atmospheres is inefficient and the concomitant detection of $\mathrm{O}_{2}$ or $\mathrm{O}_{3}$ with $\mathrm{NH}_{3}$ (9 and $11 \mu \mathrm{m}$ in the Darwin window) or $\mathrm{CH}_{4}(7.5 \mu \mathrm{m})$ would strongly suggest biological activity.

\subsection{Consequences for Darwin and TPF}

\subsubsection{Maximum $\mathrm{O}_{2}$ abiotic production}

Looking back to Table 3, we note that $\mathrm{O}_{2}$ can become, through photochemical production in one case (case $\mathrm{E}$, i.e. 4 bar dry $\mathrm{CO}_{2}$ atmosphere), a major component of the atmosphere, reaching $x_{\mathrm{O} 2} \sim 5 \%$. This result is close to the $x_{\mathrm{O} 2}=3.9 \%$ found by Nair et al. (1994) for a lower pressure dry $\mathrm{CO}_{2}$ atmosphere (dry Mars), found with an equilibrium model. Although this $5 \%$ level is somewhat below the $20 \%$ level of present terrestrial $\mathrm{O}_{2}$, this questions our ability to discriminate between abiotic and biologic $\mathrm{O}_{2}$ origin. This is a crucial point when one considers searching for $\mathrm{O}_{2}$ photosynthetic life by the direct and unique detection of $\mathrm{O}_{2}$. Note however that the corresponding atmospheres are extreme and may be unlikely cases: is it possible to build up a $\mathrm{CO}_{2}$ atmosphere completely devoid of $\mathrm{H}_{2} \mathrm{O}$ ? Even Mars and Venus have traces of water vapor. And many other compounds found in planetary atmospheres (sulfur or chlorine compounds, for example) can catalyse, at trace levels, the reverse process, reforming $\mathrm{CO}_{2}$ from $\mathrm{CO}$ and $\mathrm{O}_{2}$.

\subsubsection{Is case $G$ (permanent water supply) a realistic false positive case?}

Coming back to case $\mathrm{G}$, where, although marginal, a triple signature might appear, we stress the ad hoc nature of the situation considered: a constant influx of $\mathrm{H}_{2} \mathrm{O}$-bearing small particles or larger bodies, the absence of an oxygen sink (no reducing species in the atmosphere, no recycling of the surface), a high UV irradiation and an efficient escape of $\mathrm{H}$ atoms. To obtain the upper limit of $1 \%$ of $\mathrm{O}_{2}$, the water influx was set to $10^{10}$ molecules $\mathrm{cm}^{-2} \mathrm{~s}^{-1}$. If delivered via hydrated dust similar to solar IDPs with an average water content of $4 \mathrm{wt} \%$ (Maurette et al. 2000), this flux implies the infall of $1.9 \times 10^{9}$ tons $\mathrm{yr}^{-1}$ on the whole Earth. This is $3 \times 10^{4}$ higher than the current flux $\left(40000 \pm 20000\right.$ tons $\mathrm{yr}^{-1}$, Love \& Brownlee 1993). Earth might have experienced such a high flux only during the Late Heavy Bombardment (Maurette et al. 2000; Love \& Brownlee 1993). So high delivery presupposes a very dusty interplanetary environment which lasts less than $400 \mathrm{My}$ around main-sequence stars (Habing et al. 1999). Darwin and TPF will be able to detect and study terrestrial planets in the habitable zone only in the case of systems with low zodiacal emission (less than about 10 times the Solar System zodiacal light, Beichman et al. 1999). Therefore, such a case proves to be restricted to very young systems and moreover, probably non-observable in the mid-infrared. Moreover, although we considered only a deposition of pure water vapor, delivering water this way is also a source of highly reducing species. Indeed, cometary matter contains nearly as much mass in refractory complex organics than in water ice (Greenberg 2000) and collected micrometeorites have an average content of organic carbon of 3 wt\% (Maurette 1998). Such species, delivered at the same time as water, would prevent any $\mathrm{O}_{2}$ accumulation.

\subsubsection{The $\mathrm{CO}_{2}$ masking of $\mathrm{O}_{3}$ : Advantages and disadvantages}

We have seen (cases B, C, D and E) that when the $\mathrm{CO}_{2}$ pressure is high enough to photochemically produce an IR-absorbing ozone layer $\left(P_{\mathrm{CO}_{2}}>50\right.$ mbar for a dry atmosphere, $P_{\mathrm{CO}_{2}}>1$ bar for a humid atmosphere), high $\mathrm{CO}_{2}$ pressure bands (centered at about 7.3, 7.9, 9.4 and $10.5 \mu \mathrm{m})$ affect the thermal spectrum. With Darwin resolution $(R \sim 20)$ and signal-to-noise ratio $(S N R<10)$, the two $\mathrm{CO}_{2}$ features arising on both side of the $9.6 \mu \mathrm{m}$ band hide the $\mathrm{O}_{3}$ signature. By masking the abiotic ozone it sustains, $\mathrm{CO}_{2}$ masks also the potential "false positive imposters" that photochemistry could produce in the midinfrared.

For higher spectral resolution than foreseen for Darwin spectra in Fig. 6 show that $\mathrm{O}_{3}$ and $\mathrm{CO}_{2}$ features can in principle be distinguished, even in the case of a humid atmosphere. However, the "triple signature" criterion still allows in this case to trace their possible abiotic origin, when high $\mathrm{CO}_{2}$ pressure bands are present. On the other hand, the masking effect (at low resolution) as well as the rejection of spectra with high $\mathrm{CO}_{2}$ pressure (at high resolution) can produce "false negatives", as they lead one to reject truly photosynthetic ecosystems that would be detectable under a $\mathrm{CO}_{2}$-poor atmosphere (Selsis 2002).

If one considers it more important to avoid false positive detections than to miss inhabited planets, the masking of abiotic $\mathrm{O}_{3}$ and then of false positive detection is clearly an advantage, as this eliminates several potentially ambiguous cases.

\subsubsection{Is the Darwin strategy validated?}

Within the framework of our approach, does the Darwin concept still appear to be validated with respect to the risk of false positive detection? The answer is clearly yes. Relying on our simulations and discussions above, it turns out that the simultaneous signature of $\mathrm{H}_{2} \mathrm{O}, \mathrm{CO}_{2}$ and $\mathrm{O}_{3}$ within Darwin's spectral window cannot be due to abiotic photochemistry. With an additional criterion imposing the absence of high $\mathrm{CO}_{2}$ pressure bands, this triple biomarker can be extrapolated to future high performance instruments working in the mid-infrared range. Searching for the triple IR signature of $\mathrm{O}_{3}, \mathrm{CO}_{2}$ and $\mathrm{H}_{2} \mathrm{O}$ with a Darwin-like instrument appears more robust than a direct but unique detection of $\mathrm{O}_{2}$. Indeed, while $\mathrm{O}_{2}$ can become 
abiotically a major atmospheric component (up to few percents) $\mathrm{O}_{3}$ cannot be detected in such cases at the same time as $\mathrm{H}_{2} \mathrm{O}$ and $\mathrm{CO}_{2}$, due to the masking effect of $\mathrm{CO}_{2}$, and/or to the catalytic cycles destroying $\mathrm{O}_{3}$ and following $\mathrm{H}_{2} \mathrm{O}$ photolysis. Thus, through the triple signature, Darwin effectively filters out false positive detections in all the cases. Moreover,

- as oxygenic photosynthesis extracts $\mathrm{O}_{2}$ from $\mathrm{H}_{2} \mathrm{O}$ and fix carbon from $\mathrm{CO}_{2}$;

- as life appears to be, as far as we know it, indissociable from $\mathrm{H}_{2} \mathrm{O}$;

- as $\mathrm{CO}_{2}$ is a constituent of all the known terrestrial planet atmospheres and an expected constituent of habitable extrasolar planets (Kasting et al. 1993);

- and as $\mathrm{O}_{3}$ is a powerful, logarithmic, tracer of $\mathrm{O}_{2}$ (Léger et al. 1993);

searching for this triple signature in quest of photosynthetic sources of $\mathrm{O}_{2}$ is not a restrictive strategy when compared to search for $\mathrm{O}_{2}$, or $\mathrm{O}_{3}$, alone.

Furthermore, the relevance of this mid-IR triple signature is strengthened when considering that, in our simulations, the abiotic production of $\mathrm{O}_{2}$ and $\mathrm{O}_{3}$ was optimized on purpose. Adding more realistic processes or compounds (weathering and chemical interaction with rocks, delivery of external matter, volcanic emissions) to these "clean" atmospheres diminishes the possible amounts of these two molecules. This trend was noted when simulating early Earth cases (C, D) and it clearly makes mid-infrared false positive detection even more unlikely.

\section{Conclusion}

We adressed here the question of abiotic photochemical production of $\mathrm{O}_{2}$ and $\mathrm{O}_{3}$ and the astrobiological relevance of the detection of these molecules on extrasolar planets by future space observatories (Darwin and TPF). The two possible sources leading to an $\mathrm{O}_{2}$ accumulation are the photolysis of $\mathrm{CO}_{2}$, and of $\mathrm{H}_{2} \mathrm{O}$ when associated with hydrogen escape. We first showed qualitatively that these two mechanisms interfere with each other, and are thus limited in habitable planet atmospheres, where both $\mathrm{CO}_{2}$ and $\mathrm{H}_{2} \mathrm{O}$ are expected. To tackle quantitatively the problem, we developed new photochemical and thermal models of planetary atmospheres. The simulation were conducted on 7 main types of terrestrial planet atmospheres (presented in Table 3), which include present Mars and plausible early Earth and Mars atmospheres.

According to our simulations, the $\mathrm{CO}_{2}$ photolysis proved to be an efficient way to build up a significant oxygen level in two general cases. The first one is a dry atmosphere, where the recombination of $\mathrm{CO}_{2}$ is not catalysed by the products of $\mathrm{H}_{2} \mathrm{O}$ photolysis. The second is a humid atmosphere made of more than one bar of $\mathrm{CO}_{2}$ : in this case the temperature profile does not allow $\mathrm{H}_{2} \mathrm{O}$ to reach altitudes where it could be photolysed. In such cases, $\mathrm{O}_{2}$-rich atmospheres with an $\mathrm{O}_{3}$ layer as dense as on Earth can be built without the intervention of life.
However, we demonstrated that the search for life remains possible, at least within the wavelength range of the Darwin instrument $(5-20 \mu \mathrm{m})$, by selecting only the spectra displaying the simultaneous signature of $\mathrm{CO}_{2}, \mathrm{H}_{2} \mathrm{O}$ and $\mathrm{O}_{3}$, that we called the "triple signature". Indeed, the need for water to make the planet habitable and the $\mathrm{CO}_{2}$ masking effect at Darwin resolution filter out any $\mathrm{O}_{2}$-rich atmosphere built from $\mathrm{CO}_{2}$ photolysis. Moreover, future instruments of higher spectral resolution, able to resolve the $\mathrm{O}_{3}$ signature among the $\mathrm{CO}_{2}$ bands, will also allow to discount ambiguous cases, as the presence of these high pressure $\mathrm{CO}_{2}$ bands warns the observer about the possible abiotic origin of $\mathrm{O}_{3}$.

We also investigated an eventual false positive detection due to the enrichment in $\mathrm{O}_{2}$ that follows the photolysis of water vapor associated to hydrogen escape. In this case, the production of $\mathrm{O}_{2}$ is maintained by a constant delivery of water in the upper atmosphere via hydrated particles. It is possible to "tune" the model in such a way that a significant build-up of $\mathrm{O}_{2}$ occurs. However, besides the fact that the required conditions are unrealistic or result in a non-observable case (due to large zodiacal emission), $\mathrm{O}_{3}$ is destroyed by the products of $\mathrm{H}_{2} \mathrm{O}$ photodissociations while $\mathrm{O}_{2}$ is produced. This prevents the formation of a detectable ozone layer.

We have thus demonstrated the robustness of the biogenic $\mathrm{O}_{2}$ detection scheme based on the triple $\mathrm{CO}_{2}-\mathrm{H}_{2} \mathrm{O}$ $\mathrm{O}_{3}$ IR signature that we propose for Darwin, as the risk of false positive proves to be low. We showed in contrast that relatively high $\mathrm{O}_{2}$ content can be reached abiotically (up to 50 mbar in our sample), which could be a major concern for experiments aiming at detecting photosynthetic life using information on $\mathrm{O}_{2}$ alone. Note that searching the triple signature instead of $\mathrm{O}_{3}$ alone is not restrictive as $\mathrm{H}_{2} \mathrm{O}$ and $\mathrm{CO}_{2}$ are expected in habitable planets and display strong IR bands.

Although it may be more important to avoid "imposters" than to miss an ambiguous signal from some inhabited planet, "false negative cases" and the conditions under which oxygenic photosynthesis can effectively transform the atmosphere have also to be discussed (Selsis 2002). For the Earth itself, the triple signature would have allowed a remote detection of life for only about half of its history: the almost equally long period where biogenic $\mathrm{CH}_{4}$ was probably the main greenhouse gas should be studied in great detail when trying to search for life beyond photosynthetic species. All these questions are very important for the optimal design of any ground or space experiment like Darwin and TPF aiming at the observation and search for biosignatures in the atmospheres of terrestrial exoplanets; in all cases photochemical models will be of great help, as we have seen here.

Acknowledgements. This work was funded by Programme National de Planétologie and GDR Exobiologie (INSU/CNRS). We thank Dr. A. Léger and Dr. M. Gargaud for critically reading the draft of this paper and Dr. W. Traub for his numerous and constructive comments that led to this final version. 


\section{References}

Angel, J. R. P., Cheng, A. Y. S., \& Woolf, N. J. 1986, Nature, 322,341

Atreya, S. K., \& Gu, Z. G. 1994, J. Geophys. Res., 99, 13133

Baragiola, R., \& Bahr, D. A. 1998, J. Geophys. Res., 103, 25865

Barker, E. S. 1972, Nature, 238, 447

Barth, C. A., Hord, C. W., Stewart, A. I., et al. 1973, Science, 179,795

Beichman, C. A., Woolf, N. J., \& Lindensmith, C. A. (eds.), 1999, The Terrestrial Planet Finder (TPF): a NASA Origins program to search for habitable planets (JPL Publications)

Berk, A., Bernstein, L. S., \& Robertson, D. C. 1989, MODTRAN: A MODerate resolution for LOWTRAN 7, Technical report, Air Force Geophysics Laboratory, Bedford, Mass

Bjoraker, G. L., Mumma, M. J., \& Larson, H. P. 1989, Bull. Amer. Astron. Soc., 21, 990

Borucki, W. J., Koch, D. G., Dunham, E. W., \& Jenkins, J. M. 1997, in Planets Beyond the solar system and the Next Generation of Space Missions, ASP Conf. Ser., 119, 153

Bracewell, R. N., 1978, Nature, 274, 780

Canuto, V. M., Levine, J. S., Augustsson, T. R., \& Imhoff, C. L. 1982, Nature, 296, 816

Carleton, N. P. \& Traub, W. A. 1972, Science, 177, 988

Carr, M. H. 1983, Icarus, 56, 476

Carr, M. H. 1986, Icarus, 68, 187

Charbonneau, D., Brown, T. M., Latham, D. W., \& Mayor, M. 2000, ApJ, 529, L45

Charbonneau, D., Brown, T. M., Noyes, R. W., \& Gilliland, R. L. 2001, ApJ, accepted

Clancy, R. T., Grossman, A. W., \& Muhleman, D. O. 1992, Icarus, 100,48

Clancy, R. T., Wolff, M. J., \& James, P. B. 1999, Icarus, 138, 49

Coakley, J. A. 1977, J. Atmos. Sci., 34, 1402

Commeyras, A., Collet, H., Boiteau, L., et al. 2002, Polymer Int., submitted

Connes, P., Noxon, J. F., Traub, W. A., \& Carleton, N. P. 1979, ApJ, 233, L29

Dauphas, N., Robert, F., \& Marty, B. 2000, Icarus, 148, 508

Deeg, H. J., Favata, F., Penny, A., and Eddington Science Team 2000, in IAU Symp., 202, E108

DeMore, W. B., Sander, S. P., Golden, D. M., et al. 1997 (JPL Publications)

Dobrijevic, M., \& Parisot, J. P. 1998, Planet. Space Sci., 46, 491

Espenak, F., Mumma, M. J., Kostiuk, T., \& Zipoy, D. 1991, Icarus, 92, 252

Feuchtgruber, H., Lellouch, E., de Graauw, T., et al. 1997, Nature, 389, 159

Floyd, L. E., Reiser, P. A., Crane, P. C., et al. 1998, Sol. Phys., 177,79

Forget, F., \& Pierrehumbert, R. T. 1997, Science, 278, 1273

Galimov, E. M. 2000, Icarus, 147, 472

Gough, D. O. 1981, Sol. Phys., 74, 21

Greenberg, J. M. 2000, Earth, Moon, Planets, 82-83, 313

Habing, H. J., Dominik, C., Jourdain de Muizon, M., et al. 1999, Nature, 401, 456

Hall, D. T., Feldman, P. D., McGrath, M. A., \& Strobel, D. F. 1998, ApJ, 499, 475
Hall, D. T., Strobel, D. F., Feldman, P. D., McGrath, M. A., \& Weaver, H. A. 1995, Nature, 373, 677

Hoffman, N. 2000, Icarus, 146, 326

Holland, H. D. 1994, in Early life on Earth, Nobel Symp., No. 84, 237

Isaksen, I. S. A., Midtbo, K. H., Sunde, J., \& Crutzen, P. J. 1977, Geophys. Norveg., 31, 11

Johnson, R. E. 1990, Energetic Charged-Particle Interactions with Atmospheres and Surfaces, Energetic ChargedParticle Interactions with Atmospheres and Surfaces (Springer-Verlag Berlin)

Johnson, R. E. 1999, J. Geophys. Res., 104, 14179

Johnson, R. E., \& Jesser, W. A. 1997, ApJ, 480, L79

Kahn, R. 1985, Icarus, 62, 175

Kass, D. M., \& Yung, Y. L. 1999, Geophys. Res. Lett., 26, 3653

Kasting, J. F. 1988, Icarus, 74, 472

Kasting, J. F. 1993, Science, 259, 920

Kasting, J. F. 1995, Planet. Space Sci., 43, 11

Kasting, J. F., Pollack, J. B., \& Crisp, D. 1984, J. Atmos. Chem., 1, 403

Kasting, J. F., Whitmire, D. P., \& Reynolds, R. T. 1993 Icarus, 101, 108

Krasnopolskii, V. A., Krysko, A. A., Rogachev, V. N., \& Parshev, V. A. 1976, Cosmic Res., 14, 789

Krasnopolsky, V. A. 1993, Icarus, 101, 313

Krasnopolsky, V. A., \& Zahn, U. V. 1986, Photochemistry of the Atmospheres of Mars and Venus (Springer-Verlag)

Le flochmoën, E. 1997, Ph.D. Thesis, Université de Bordeaux I

Léger, A., Mariotti, J. M., Mennesson, B., et al. 1996, Icarus, 123,249

Léger, A., Ollivier, M., Altwegg, K., \& Woolf, N. J. 1999, A\&A, 341, 304

Léger, A., Pirre, M., \& Marceau, F. J. 1993, A\&A, 277, 309

Lezeaux, O. 1999, Ph.D. Thesis, Université Bordeaux I

Lindner, B. L. 1985, Ph.D. Thesis, Colorado Univ., Boulder

Love, S. G., \& Brownlee, D. E. 1993, Science, 262, 550

Maurette, M. 1998, Origins Life Evol. Biosphere, 28, 385

Maurette, M., Duprat, J., Engrand, C., et al. 2000, Planet. Space Sci., 48, 1117

Mayor, M., \& Queloz, D. 1995, Nature, 378, 355

McKay, C. P., Toon, O. B., \& Kasting, J. F. 1991, Nature, 352,489

Mills, F. P. 1999, J. Geophys. Res., 104, 30757

Mojzsis, S. J., Arrhenius, G., McKeegan, K. D., et al. 1996, Nature, 384, 55

Mojzsis, S. J., Harrison, T. M., \& Pidgeon, R. T. 2001, Nature, 409, 178

Nair, H., Allen, M., Anbar, A. D., Yung, Y. L., \& Clancy, R. T. 1994, Icarus, 111, 124

Navarro-Gonzalez, R., Molina, M. J., \& Molina, L. T. 1998, Geophys. Res. Lett., 25, 3123

Nisenson, P., \& Papaliolios, C. 2001, ApJ, 548, L201

Noll, K. S., Johnson, R. E., Lane, A. L., Domingue, D. L., \& Weaver, H. A. 1996, Science, 273, 341

Noll, K. S., Roush, T. L., Cruikshank, D. P., Johnson, R. E., \& Pendleton, Y. J. 1997, Nature, 388, 45

Noxon, J. F., Traub, W. A., Carleton, N. P., \& Connes, P. 1976, ApJ, 207, 1025

Ollivier, J. L., Dobrijévic, M., \& Parisot, J. P. 2000, Planet. Space Sci., 48, 699

Ollivier, M. 1999, Ph.D. Thesis, Université de Paris XI

Owen, T. 1980, in Strategies for the search for life in the Universe, ed. M. Papagiannis (Reidel) 
Owen, T., Biemann, K., Biller, J. E., et al. 1977, J. Geophys. Res., 82, 4635

Oyama, V. I., Carle, G. C., Woeller, F., et al. 1980, J. Geophys. Res., 85, 7891

Paetzold, H. K. 1962, Mem. Soc. Roy. Sci. Liège, 452

Pavlov, A. A., Kasting, J. F., Brown, L. L., Rages, K. A., \& Freedman, R. 2000, J. Geophys. Res., 105, 11981

Pollack, J. B., Kasting, J. F., Richardson, S. M., \& Poliakoff, K. 1987, Icarus, 71, 203

Rasool, S. I., \& De Bergh, C. 1970, Nature, 226, 1037

Rees, D., Barnett, J. J., \& Labitzke, K. (eds.) 1990, COSPAR International Reference Atmosphere (CIRA): 1986, Part II: Middle Atmosphere Models (Pergamon Press, Oxford)

Rosenqvist, J., \& Chassefiere, E. 1995, Planet. Space Sci., 43, 3

Rosing, M. T. 1999, Science, 674

Rouan, D., Baglin, A., Copet, E., et al. 1998, Earth, Moon, and Planets, 81, 79

Rye, R., Kuo, P. H., \& Holland, H. 1995, Nature, 378, 603

Sagan, C., \& Mullen, G. 1972, Science, 177, 52

Sagan, C., Thompson, W. R., Carlson, R., Gurnett, D., \& Hord, C. 1993, Nature, 365, 715

Schindler, T. L., \& Kasting, J. F. 2000, Icarus, 145, 262

Seiff, A. 1982, Advances in Space Res., 2, 3

Selsis, F. 2000a, in DARWIN and Astronomy - The Infrared Space Interferometer, Stockholm, Sweden, 17-19 Nov. 1999 (ESA SP-451, May 2000), 133

Selsis, F. 2000b, Ph.D. Thesis, Université de Bordeaux I, available at anonymous server

alienor.observ.u-bordeaux.fr/pub/selsis/selsis.pdf

Selsis, F. 2002, ASP Conf. Ser., in press

Slanger, T. G., Cosby, P. C., Huestis, D. L., \& Bida, T. A. 2001, Science, 291, 463
Sleep, N. H., \& Zahnle, K. 2001, J. Geophys. Res., 106, 1373

Spencer, J. R., Calvin, W. M., \& Person, M. J. 1995, J. Geophys. Res., 100, 19049

Toublanc, D., Parisot, J.-P., Brillet, J., Gautier, D., Raulin, F., \& McKay, C. 1995, Icarus, 113, 2

Traub, W. A., \& Carleton, N. P. 1974, in Exploration of the Planetary System, IAU Symp., 65, 223

Traub, W. A., Carleton, N. P., Connes, P., \& Noxon, J. F. 1979, ApJ, 229, 846

Trauger, J. T., \& Lunine, J. I. 1983, Icarus, 55, 272

Tsang, W., \& Hampson, R. 1986, J. Phys. Chem. Ref. Data, 15,1087

Volonte, S., Laurance, R., Whitcomb, G., et al. 2000, Darwin: the Infrared space interferometer, Technical report, ESA

von Zahn, U., Kumar, S., Niemann, H., \& Prinn, R. 1983, Composition of the Venus atmosphere, Venus

Walker, J. C. G. 1977, Evolution of the atmosphere, New York: Macmillan

Walker, J. C. G., Hays, P. B., \& Kasting, J. F. 1981, J. Geophys. Res., 86, 9776

Warnatz, J. 1984, Combustion Chemistry, Chapt. 5 (SpringerVerlag)

Wehrbein, W. M., Hord, C. W., \& Barth, C. A. 1979, Icarus, 38,288

Wilde, S. A., Valley, J. W., Peck, W. H., \& Graham, C. M. 2001, Nature, 409, 175

Wolszczan, A., \& Frail, D. A. 1992, Nature, 355, 145

Yung, Y. L., \& DeMore, W. B. 1999, Photochemistry of planetary atmospheres (Oxford University Press)

Zapatero Osorio, M. R., Bejar, V. J. S., Martin, E. L., et al. 2000, Science, 290, 103

Zhang, Y., \& Zindler, A. 1993, Earth Planet. Sci. Lett., 117, 331 